\title{
Teclados de cartón. Tecnologías, identidad y comunicación entre jóvenes estudiantes de la ENOSIMAR en Mitú (Vaupés), Amazonía colombiana
}

Jaili Ivinai Buelvas Diaz

Departamento de Antropología, Facultad de Ciencias Humanas,

Universidad Nacional de Colombia. jailiivinai@gmail.com

María Sirex Consuegra Díaz-Granados Centro de Investigación e Innovación Social, Universidad Simón Bolívar. mariasirex13@gmail.com

David Felipe Henao Heuta Departamento de Antropología, Facultad de Ciencias Humanas, Universidad Nacional de Colombia.

dhneuta@gmail.com

Juliana López Cuervo Departamento de Antropología, Facultad de Ciencias Humanas, Universidad Nacional de Colombia. julopezcu@gmail.com

John Jairo Osorio Giraldo Departamento de Antropología, Facultad de Ciencias Humanas, Universidad Nacional de Colombia. jjosoriog@unal.edu.co

Laura Daniela Pardo Castellanos Departamento de Antropología e Historia, FLACSO - Ecuador. ldpardoc@gmail.com

\section{Camila Peña Gómez}

Departamento de Antropología, Facultad de Ciencias Humanas, Universidad Nacional de Colombia. campenagom@gmail.com

Fecha de finalización del trabajo: 31 de agosto de 2020 Recibido: 31 de agosto de 2020 Aceptado: 1 de diciembre de 2020 DOI: https://doi.org/10.26422/aucom.2020.0902.ivi 
Jaili Ivinai Buelvas Diaz, María Sirex Consuegra Díaz-Granados, David Felipe Henao Heuta, Juliana López Cuervo, John Jairo Osorio Giraldo, Laura Daniela Pardo Castellanos, Camila Peña Gómez

Teclados de cartón. Tecnologías, identidad y comunicación entre jóvenes estudiantes de la ENOSIMAR en Mitú (Vaupés), Amazonía colombiana

\title{
Resumen
}

Este artículo de investigación profundiza sobre la relación con las tecnologías de la información y comunicación (TIC) que tienen los jóvenes internos de la Escuela Normal Superior Indígena María Reina en Mitú (Vaupés). A través de consulta bibliográfica, entrevistas semiestructuradas, etnografía y talleres participativos analizamos críticamente la llegada los programas estatales que buscan ampliar la conectividad digital en esta región, las nociones de acceso a las TIC, los diversos conflictos en materia de conectividad y las transformaciones en las identidades y los contextos educativos producto de este relacionamiento, así como también se esbozan no solo las dificultades, sino también las potencialidades de las TIC para la identidad de los jóvenes indígenas de Mitú, Vaupés.

Palabras clave: internet, tecnologías de la información y comunicación, jóvenes indígenas, identidades, educación, Mitú, Vaupés.

\section{Cardboard keyboards. Technologies, identity, and communication between young students at the ENOMISAR school in Mitú, Vaupés, within Colombia's Amazon region}

\begin{abstract}
This investigative article looks at the relationship between young students at the María Reina Indigenous Superior Normal School (ENOMISAR, by its Spanish acronym) in Mitú, Vaupés, in Colombia, and the information and communication technologies (ICTs) they interact with. Through a review of the relevant literature, semi-structured interviews, ethnographic studies, and participatory workshops, we critically analyzed several topics. These included: the arrival of state-funded programs meant to broaden digital connectivity in the region, access to ICTs, conflicts around connectivity and identity transformation, and the educational situations that arise out of this conflict. We also suggest the difficulties and potentialities that ICTs bring to the table when it comes to the identity of indigenous youth in Mitú, Vaupés.

Keywords: Internet, information and communication technologies, indigenous youth, identity, education, Mitú, Vaupés.

\section{Teclados de papelão. Tecnologias, identidade e comunicação entre jovens estudantes da ENOSIMAR em Mitú (Vaupés), Amazônia colombiana}

\section{Resumo}

Este artigo pesquisa a relação com as tecnologias de informação e comunicação (TIC) que têm os jovens internos da Escola Normal Superior Indígena Maria Reina de Mitú (Vaupés). Por meio de consulta bibliográfica, entrevistas semiestruturadas, etnografia e oficinas participativas, analisamos criticamente a chegada de programas governamentais que buscam ampliar a conectividade digital nesta região, as noções de acesso às TIC, os diversos conflitos em termos de conectividade e as transformações nas identidades e contextos educacionais decorrentes dessa relação, bem como não só as dificuldades, mas também as potencialidades das TIC para a identidade dos jovens indígenas de Mitú, Vaupés. 
Palavras chave: internet, tecnologias de informação e comunicação, juventude indígena, identidades, educação, Mitú, Vaupés.

\section{Introducción}

Frente al escenario de conectividad globalizada y de un universo digital en expansión, el uso de internet ha transformado nuestras realidades materiales, nuestra vida cotidiana e incluso nuestra forma de relacionarnos interpersonalmente. Sin embargo, hay escenarios territoriales donde el acceso al mundo digital es limitado o inexistente. Así, lugares alejados geográficamente, excluidos en la historia de las dinámicas nacionales -o territorios rurales- han tenido una incorporación distinta a este mundo digital. Poco a poco, la conectividad ha llegado a estas regiones y el uso de las redes sociales, de las formas digitales de comunicación y de internet en general se ha ampliado entre la población, integrándose de maneras irregulares a la vida diaria, constituyendo un espacio en el cual se negocia simbólicamente lo global para integrarlo a sus prácticas cotidianas, expresando marginalmente las características de una modernidad globalizada (Appadurai, 2001).

Este es el caso de Mitú, la capital del departamento del Vaupés, ubicado en la Amazonía colombiana. Si bien el departamento del Vaupés, debido a su localización geográfica y a las lógicas centralistas del Estado colombiano, se encuentra en un territorio periférico en el cual muchas de las dinámicas sociales distan de las que se expresan en la cotidianidad de los territorios centrales del país, el mundo digital se encuentra presente en la vida diaria de los jóvenes del departamento. A pesar de que el acceso a internet y al mundo digital es muy limitado, esto no ha impedido que la población de Mitú, y sus jóvenes, accedan a este mundo digital.

Este artículo condensa algunas de las reflexiones surgidas del proyecto "Identidades en tránsito: entre el mundo digital y la vida en comunidad Jóvenes, territorio y comunicación en el Vaupés", que busca ahondar en las formas en las que el uso de internet y de las nuevas tecnologías (TIC) se ha venido incorporando a la vida cotidiana de jóvenes internos de la Escuela Normal Superior Indígena María Reina (en adelante, ENOSIMAR), en su proceso de transición migratoria de distintas comunidades rurales con nula conectividad hacia la capital del departamento, Mitú, para continuar con su formación educativa.

Abordar las dinámicas que ha generado la tecnología y el uso de internet en la vida de estos jóvenes a raíz de su vivencia escolar en Mitú, y las relaciones que han establecido con el mundo digital, nos permite acercarnos a comprender el impacto que han tenido las tecnologías en territorios como este, en la mentalidad de los jóvenes, en sus estilos y condiciones de vida, en la identidad y en sus deseos y aspiraciones. 
Jaili Ivinai Buelvas Diaz, María Sirex Consuegra Díaz-Granados, David Felipe Henao Heuta, Juliana López Cuervo, John Jairo Osorio Giraldo, Laura Daniela Pardo Castellanos, Camila Peña Gómez

Teclados de cartón. Tecnologías, identidad y comunicación entre jóvenes estudiantes de la ENOSIMAR en Mitú (Vaupés), Amazonía colombiana

\section{Metodología}

Esta investigación fue desarrollada en la ENOSIMAR entre los meses de octubre de 2019 y abril de 2020. Una de las principales apuestas del proyecto "Identidades en tránsito..." ha sido la de desarrollar una metodología de investigación participativa para implementar con los estudiantes integrantes del equipo de trabajo. Con ese fin, diseñamos una serie de técnicas con enfoques prácticos que fueron ejecutadas con jóvenes internos e internas de la Escuela Normal Superior de Mitú, con el objetivo de levantar comunitaria y participativamente reflexiones aplicadas a su contexto práctico y cotidiano (Wicks, Reason, y Bradbury, 2008). Sin embargo, en medio del desarrollo de la investigación, nos sorprendieron las medidas tomadas para contener el avance del virus COVID-19 en el territorio colombiano. Estas medidas exigían el tránsito hacia la virtualidad en un contexto en el que las condiciones materiales para ello eran precarias. Este panorama resultó revelador para discutir nuestras principales preocupaciones al emprender este proyecto.

Se realizó un trabajo de campo intensivo en esta institución, se desarrollaron talleres participativos con los jóvenes y entrevistas tanto a funcionarios públicos departamentales como a educadores y estudiantes para obtener una mirada amplia que involucrase diversas posiciones sobre el uso de internet y de las TIC tanto en la ENOSIMAR como en el departamento. La observación participante, metodología clásica de la antropología, y entendida como un proceso no de recolección de datos, sino de aprendizaje transformativo de la experiencia en campo (Ingold, 2015), fue esencial para participar de la vida cotidiana, identificar los procesos comunitarios de los jóvenes y descubrir los elementos más relevantes dentro de los relatos de la población. Para ello ,se brindaron talleres de técnicas de investigación cualitativa a los jóvenes, principalmente sobre la aplicación de entrevistas estructuradas y semiestructuradas, y la elaboración de notas y diarios de campo con sus propias reflexiones. Así, las notas de campo y el diario de campo fueron un instrumento útil para la sistematización de la información recogida de manera participativa y para la posterior creación de categorías de análisis, derivadas de la experiencia en campo (Bernard, 1995).

Este trabajo de campo fue respaldado por una revisión de los programas relacionados con las políticas de acceso a las TIC en Vaupés. Este material constituye el corpus que alimenta la presente investigación.

Para acotar la discusión con estas ideas es inevitable señalar que nuestro proceso de investigación-participación se vio súbitamente interrumpido por la contingencia sanitaria y social del COVID-19, mucho más cuando al momento de la escritura de este artículo nos encontrábamos en distintos lugares del país, intercomunicados por computadores, cada uno viviendo su aislamiento. La declaratoria de la cuarentena y el consiguiente aislamiento social obligatorio, que nos confinó en nuestras casas, nos 
impidió seguir realizando los encuentros y talleres ya que las clases fueron suspendidas; y los jóvenes, enviados a sus casas, en principio, bajo el pretexto de adelantar las vacaciones. Luego, frente a la necesidad de extender el período de confinamiento doméstico, el Ministerio de Educación estableció algunos lineamientos para empezar a implementar un improvisado modelo de "educación virtual", en un país que no tiene las condiciones necesarias para ello, pues en Colombia no hemos logrado siquiera afianzar una educación presencial de calidad en los territorios periféricos; ahora, con todas las discusiones presentadas, somos pesimistas en imaginar, con la urgencia que se necesita, un sistema de educación a distancia de calidad.

Uno de los profesores nos compartía la narración que da título a este artículo y que revela la situación al interior de las escuelas del departamento:

Esta Normal creo que necesita una sala de informática de este siglo XXI, con todas las herramientas, con todos los accesorios, para yo decir, "uy, tengo las herramientas, voy a sacar lo mejor de los estudiantes". Pero en ocasiones hay veces que uno no tiene cómo, porque hace unos años teníamos informática, pero funcionaban por ahí 5 equipos y eran de esos obsoletos grandes, los donó [Computadores para Educar], esos la mayoría llegaban inservibles, uno se encontraba a veces con eso y tenía que pedirles a los alumnos: bueno, listo, hágame un teclado en cartón, pero ¿el chino qué aprende allí en un dibujo? ${ }^{1}$

\section{Vaupés, un territorio en las fronteras del Estado-nación}

Vaupés, uno de los seis departamentos que conforman la Amazonía colombiana, está ubicado al nordeste de la selva haciendo la transición hacia la Orinoquía y los Llanos. Limita al norte y noroeste con los departamentos de Guainía y Guaviare, al sur con el Amazonas y el Caquetá y al este sirve de frontera nacional con Brasil. El paisaje predominante son los ríos y caños de aguas negras (con abundante arrastre de sedimentos), enmarcados en extensos kilómetros de doseles verdes, penetrados esporádicamente por piedras inmensas coronadas en la punta con vegetación, que sobresalen aisladas o en serranías y sabanas. El río Vaupés es el principal de los que atraviesan la región.

Mitú es la capital del departamento; está ubicada a la margen derecha bajando por el medio Vaupés. Las vías de acceso son solo aéreas, fluviales y caminos de a pie. Esta área es territorio ancestral del pueblo cubeo, aunque hoy en día la habitan familias de más de 25 etnias diferentes sumadas a los colonos mestizos que han llegado en mayor medida atraídos por las dinámicas comerciales y laborales en épocas de bonanza (de caucho, balata, coca y minerales, entre otros productos) y como consecuencia de las actividades de evangelización.

Entrevista realizada el 24 de marzo de 2020 a un profesor en su domicilio en la ciudad de Mitú. 
Jaili Ivinai Buelvas Diaz, María Sirex Consuegra Díaz-Granados, David Felipe Henao Heuta, Juliana López Cuervo, John Jairo Osorio Giraldo, Laura Daniela Pardo Castellanos, Camila Peña Gómez

Teclados de cartón. Tecnologías, identidad y comunicación entre jóvenes estudiantes de la ENOSIMAR en Mitú (Vaupés), Amazonía colombiana

Para comprender la configuración del espacio social contemporáneo en Mitú es necesario analizar las dinámicas de colonización, evangelización y explotación económica en la historia del poblamiento regional del Vaupés, que puede darnos una idea de las dinámicas sociopolíticas y culturales en las que se enmarca el modelo educativo que rige actualmente sobre las poblaciones indígenas del departamento. Es necesario tener en cuenta el contexto de múltiples intentos de dominación que hace parte de un patrón de presencia diferenciada del Estado colombiano sobre los espacios de frontera, debido a que, en la región, los aparatos del Estado constituyen un actor local más en diálogo con los distintos poderes que regulan la vida social, política y económica del departamento. Así, el Estado carece del monopolio de la fuerza, y en su tentativa de establecerse como el actor territorial hegemónico, manifiesta su presencia a través de débiles instituciones y una fuerza armada que concentra también actividades gubernamentales (González, 2003; González, Bolívar y Vásquez, 2003; Serje, 2011; Trejos Rosero, 2015).

Históricamente, la región del Vaupés ha experimentado procesos sociales de ocupación que se remontan a los pleitos territoriales entre españoles y portugueses por la dominación de los territorios amazónicos en el siglo XVIII. Posteriormente, el ingreso interrumpido de misiones católicas evangelizadoras generó un patrón de auge y repliegue en el que las comunidades indígenas desplegaban estrategias de resistencia frente a los abusos civilizatorios de las congregaciones religiosas, en la búsqueda de conservar su pensamiento y su cultura. Estos constantes ciclos estuvieron marcados por la dificultad de "reducir" a los pueblos indígenas y generaron un patrón de poblamiento disperso, en el que las poblaciones se remontaban para huir de los intentos de cristianización.

Sin embargo, hacia mediados del siglo XIX, lograron estabilizarse las primeras misiones carmelitas con la fundación de numerosos pueblos sobre el río Vaupés, convirtiéndose en epicentros para el avance de la colonización blanca sobre los territorios indígenas, aunque seguían presentándose constantes rebeliones y levantamientos por parte de los pueblos sometidos, pues cuando las misiones se sucedían entre sí, los sacerdotes "encontraban el trabajo de sus antecesores en ruinas" (Hugh-Jones, 1981, p.34). A la par del control comercial, no fueron escasos los intentos de reconducir las dinámicas culturales y sociales de las poblaciones indígenas. La narrativa histórica nos muestra que los mayores conflictos a los que se enfrentaron los evangelizadores consistían en desafiar las lógicas religiosas de los nativos. Con el cierre de las misiones, algunas comunidades optaron por establecer relaciones comerciales con las poblaciones mestizas. Hubo también algunas expediciones punitivas por parte de las autoridades estatales en las que, sin la protección misionera, los indígenas se vieron expuestos a los vejámenes de los militares (raptos, asesinatos, violaciones, incendios y saqueos de 
Austral Gmunicación

Volumen 9, número 2 (Diciembre de 2020): 635-675. ISSN 2313-9129

las aldeas) y decidieron abandonar los poblados para remontarse sobre los principales ríos y construir malocas en la selva (Hugh-Jones, 1981, p. 36).

Por ende, no fue sino hasta principios del siglo XX que las misiones lograron consolidarse con el arribo de salesianos y monfortianos; desde entonces, la presencia misionera se volvió permanente. En 1910, la Prefectura Apostólica de Río Negro fue creada después de que los salesianos se establecieran en el área e hicieran visitas periódicas al Tiquié, donde la influencia misionera había desaparecido muy rápidamente y los indígenas habían vuelto a sus formas de vida tradicional. En 1912, los monfortianos entraron al Vaupés y el 15 de agosto de 1914 se fundó Monfort de Papurí como centro de todas las misiones. Bajo el auspicio del padre Kock, destruyeron igualmente las malocas y fundaron puestos de misión con casas y una capilla. Años después, emprendieron una vez más su tarea usando un sistema nuevo y mucho más efectivo; en vez de concentrar a la población indígena en aldeas, los salesianos construyeron un pequeño número de centros misioneros cada uno con un internado para los niños indígenas.

\section{Internados y asimilación cultural: la ENOSIMAR como proyecto de nación}

Con la consolidación de las estructuras misioneras a comienzos del siglo XX, simultáneas a los años de auge del caucho, el Gobierno nacional expidió el Decreto 614 de 1918 (El Presidente de la República de Colombia, 1918), que establecía que los indígenas "no estarán sujetos a las leyes comunes de la República y serán gobernados en forma extraordinaria por los Misioneros encargados de su reducción", como respuesta a las constantes denuncias de los misioneros sobre abusos de colonos y caucheros blancos cometidos contra la población indígena, que impedía la actividad de las misiones (Sánchez Cardozo, s.f.). Con esta decisión, el Estado colombiano delegaba su responsabilidad administrativa en la Iglesia católica y garantizaba el establecimiento de un orden territorial que le permitiera asegurar la precaria anexión de estos territorios dentro de la configuración sociojurídica de la nación. Durante esos años, los misioneros viajaron por la selva reclutando niños y jóvenes para llevarlos a los internados.

En 1930, con la decadencia de la industria del caucho y la balata, los blancos abandonaron la región y los indígenas retornaron a habitar las orillas de los grandes ríos Tiquié y Vaupés. Para ese año, los niños que asistían a la escuela misionera eran casi todos blancos. Según Hugh-Jones (1981), esta situación se transformó a lo largo de los 30 años siguientes, así que, para 1960, el 80\% de la población de los internados eran niños indígenas. En 1935, Mitú fue designada capital de la entonces Intendencia del Vaupés, y con la construcción de la pista de aterrizaje desde entonces se mantuvo conectada con el resto del país. Los misioneros monfortianos estuvieron al frente de la misión y eran los únicos que desarrollaban la labor de enseñanza que, simultáneamente, afianzaba la 
Jaili Ivinai Buelvas Diaz, María Sirex Consuegra Díaz-Granados, David Felipe Henao Heuta, Juliana López Cuervo, John Jairo Osorio Giraldo, Laura Daniela Pardo Castellanos, Camila Peña Gómez

Teclados de cartón. Tecnologías, identidad y comunicación entre jóvenes estudiantes de la ENOSIMAR en Mitú (Vaupés), Amazonía colombiana

noción ideológica de "colombianidad" en las comunidades aledañas, hasta que en 1945 fueron reemplazados por los misioneros javerianos.

A partir de ese momento, la enseñanza de la colombianidad se volvió supremamente eficiente en construir una noción de unidad con el territorio colombiano en Vaupés. Celebraciones como el "día de la colombianidad" se transformaron en una narrativa central en la agenda cultural y pedagógica de los internados. Esto es especialmente interesante en virtud de que, en el contexto del departamento, es necesario reforzar simbólicamente la pertenencia a una comunidad imaginada dentro de los límites de un territorio nacional, debido a la debilidad de las instituciones (Benedict, 1983). Stephen Hugh-Jones resalta que la primera visita de un funcionario estatal del interior del país al territorio del Vaupés se dio en el año de 1945, lo que significó que, anterior a este evento, el único actor que promovió la integración nacional en este espacio eran las misiones, que actuaban en representación de un Estado colombiano que los indígenas conocían apenas nominalmente.

Es precisamente dentro de este contexto que la ENOSIMAR fue fundada en 1948 por los Misioneros Javerianos de Yarumal (MXY), que tenían por objetivo principal formar una comunidad de sacerdotes misioneros dispuestos a cristianizar a los pueblos indígenas de los territorios más apartados de Colombia. Este proyecto, sin embargo, era particular porque se enmarcaba en una empresa más amplia, concertada entre el Estado colombiano y la Iglesia católica, que actuaban en conjunto con el objetivo de ejercer un poder efectivo sobre la población indígena en las regiones más remotas de Colombia. De esta manera, se instauró un proceso civilizatorio que buscaba insertar estos vastos territorios dentro de la pretendida modernidad de la nación a través de una instrucción público-religiosa.

De modo que la creación de la ENOSIMAR se enmarcó en la fundación de escuelas normales a lo largo y ancho del país durante el período conocido como la República Liberal (1930-1946), en el que, con la intención de modernizar a Colombia, los Gobiernos de la época contrataron a académicos e intelectuales para que diseñaran currículos y planes de reforma educativa con el fin de mejorar la calidad de la educación en el país. Es en ese sentido que se intentó replicar el modelo de las escuelas normales, ${ }^{2}$ traído de Francia, entre otros, por el etnólogo Paul Rivet, con el fin de formar a los futuros profesionales, docentes e instructores que iban a tener a su cargo la educación de los niños y jóvenes de la nación. Esta fue una época caracterizada por algunas reformas sociales, políticas y económicas que buscaban la inserción de Colombia den-

\footnotetext{
2 Las escuelas normales son instituciones de educación secundaria y media vocacional que ofrecen la alternativa de un programa de formación complementaria de dos años, en los cuales los bachilleres se preparan para ejercer como docentes con el título de "normalistas".
} 
tro del concierto internacional, a la par con las naciones más "adelantadas", según las ideologías dominantes del progreso y el desarrollo capitalista.

Como resultado, la fundación de escuelas normales en muchas regiones del país significó la introducción de profundos cambios culturales y políticos, así como la transformación abrupta de las dinámicas territoriales. Si bien no se puede desconocer la importancia y el aporte de las escuelas normales para la formación de educadores que implementan prácticas pedagógicas y trasmiten sus conocimientos a las comunidades, también es cierto que estas instituciones irrumpen en la cotidianidad de las prácticas y saberes culturales, interfiriendo en muchas ocasiones con los procesos propios y enfrentándose con los saberes locales (Peña Márquez, 2011).

En muchos casos, la fundación de "escuelas normales" implicó precisamente una normalización: la homogenización cultural, la supresión de las costumbres y creencias de muchos pueblos y la imposición del cristianismo como religión y del español como lengua oficial, que supuso la desaparición y el deterioro de numerosas lenguas indígenas. Las escuelas normales fueron instrumentos de integración cultural dirigida, en términos de dominación y sujeción sociopolítica - por no decir que de sometimiento- y de aculturación y supresión de la diversidad. Con las implicaciones -en el caso de las que funcionan como internados- que el desplazamiento tiene en términos de costos económicos, impacto psicológico, cambios en las rutinas y en la alimentación y alejamiento del entorno familiar y cultural, cambios que muchas veces resultan traumáticos en jóvenes que no reciben las herramientas necesarias para integrarse al mundo "mestizo".

Durante toda la segunda mitad del siglo XX, la Normal fue consolidando su estructura bajo las directrices del Ministerio de Educación Nacional, hasta que en 2000 inició un proceso de cualificación como institución educativa formadora de formadores. En el programa de formación complementaria de la ENOSIMAR se entrenan a los educadores que se desempeñarán como docentes en las más de 100 escuelas y 15 internados del departamento, permitiendo que, en medio del intrincado panorama burocrático de la institucionalidad, por primera vez se esté delegando la educación indígena a los mismos indígenas.

Así como ocurre en Mitú con la ENOSIMAR, también hay internados en otras comunidades rurales del departamento. La figura de los internados es, en algunos casos, coordinada por comunidades religiosas y es la sucesora directa de las estructuras establecidas por las misiones monfortianas y retomadas por los javerianos. Esta continuidad contrasta con la fragmentación que se presenta en la mayoría de los procesos emprendidos al interior del departamento. Aun en la actualidad, las distancias y las dinámicas sociales dificultan la ejecución de los procesos que se plantean en la lógica centralista ante la falla del Estado colombiano en establecer una política social y económica efectiva. Estos conflictos, atravesados por las discontinuidades en los procesos étnicos, culturales 
Jaili Ivinai Buelvas Diaz, María Sirex Consuegra Díaz-Granados, David Felipe Henao Heuta, Juliana López Cuervo, John Jairo Osorio Giraldo, Laura Daniela Pardo Castellanos, Camila Peña Gómez

Teclados de cartón. Tecnologías, identidad y comunicación entre jóvenes estudiantes de la ENOSIMAR en Mitú (Vaupés), Amazonía colombiana

y educativos, están relacionados con las dinámicas propias de poblamiento y las particularidades de las experiencias de urbanización en la región de la Amazonía.

\section{Las ciudades amazónicas como espacios híbridos}

Como muestran Alexiades y Peluso (2016), el proceso contemporáneo de poblamiento y administración de la Amazonía está anclado en las lógicas del neoliberalismo y cobijado por una instalación del sistema posmoderno del capitalismo. Hoy en día, a pesar de su aislamiento geográfico dentro de los Estados nacionales, esta región está más conectada que nunca a las dinámicas urbanas, si se compara con las etapas formativas de su colonización. Con frecuencia, como es evidente en la capital del Vaupés, sus pobladores han migrado de los espacios rurales a los urbanos y han reconfigurado las dinámicas sociales de este territorio. No obstante, hablar de la urbanización de la Amazonía implica necesariamente tomar en consideración el caso de las comunidades indígenas y sus apropiaciones heterogéneas de la vida urbana.

Así, considerando las particularidades geográficas del territorio y las especificidades de los múltiples grupos humanos que lo habitan, la urbanización de la Amazonía nos lleva necesariamente a reconsiderar lo que significa lo urbano y cómo esto se articula con las realidades rurales amazónicas, conllevando una forma distinta de apropiación territorial. Para Alexiades y Peluso (2016), los espacios citadinos de la Amazonía constituyen una interfaz urbano-rural, en la que la dicotomía entre estas dos categorías de poblamiento se diluye. En el contexto de estas ciudades no puede considerarse lo urbano como un compendio de situaciones totalmente separadas de lo rural. Por el contrario, la simbiosis manifiesta entre ambos contextos se expresa en una articulación de ambientes y actores que transitan entre espacios de diversa índole que incluyen ciudades, pero también otros espacios como los bosques y los ríos. De esta suerte, la interfaz urbano-rural hace difusas las marcadas líneas con las que comúnmente se entienden lo rural y lo urbano. Con esto, los autores apuestan por una comprensión de la apropiación territorial multisituada. En contraste con otros entramados urbanos, en las ciudades amazónicas se dificulta hablar de un abandono de la vida rural, ya que el crecimiento de los municipios conlleva siempre una interacción íntima entre lo urbano y lo rural, donde lo uno no puede ser comprendido por fuera de lo otro. En el caso del Vaupés, la urbanización que retoma la estrategia de poblamiento misionero a partir de internados y centros de evangelización se transforma para consolidar distintos tipos de intercambios simbólicos y materiales con el centro del país. En estas transferencias sociales, la capital del departamento conserva sus particularidades geográficas insertadas en el contexto amazónico, pero se posiciona en la lógica urbana de la modernidad como un espacio híbrido (Alexiades y Peluso, 2016; Wanderley, 2018). 
Concordantemente con esta ambigüedad, hablar de la urbanización amazónica puede presentarse en el imaginario colectivo como una enorme contradicción, dado que conlleva el dominio de un entorno que, por definición, es indomable, al permanecer en la mentalidad común como una de las fronteras que el ser humano no ha podido quebrantar hasta hoy. Sin embargo, la realidad amazónica contemporánea pone en evidencia que esta región está cada vez más conectada al universo urbano contemporáneo, lo que revela tanto potencias como dificultades. Parte de estos conflictos radican en la convivencia de las diferentes espacialidades y temporalidades de cada grupo y proceso social en un espacio en constante resignificación y reterritorialización (Martins, 2009). Este proceso dista de ser estrictamente reciente y, al abordar la compresión del espacio amazónico de maneras plurales, este preconcepto de que la Amazonía era un escenario desurbanizado se ha visto desmitificado gracias a las investigaciones arqueológicas que han descubierto estructuras urbanas enormes. La evidencia arqueológica ha dado pruebas consistentes de grandes concentraciones poblacionales amazónicas y de una impresionante modificación de paisajes por parte de comunidades humanas en el territorio. Así, estos escenarios intensamente antropizados demuestran que el poblamiento amazónico ha vivido varios ciclos de desurbanización y urbanización, entre los cuales se destaca un doble movimiento contemporáneo que implica tanto la ruralización de lo urbano como la urbanización de lo rural. La discusión acerca de la urbanización que plantean Alexiades y Peluso (2016) aborda justamente estos ciclos, entendiendo que existen razones históricas y procesos estructurales y sociales que permiten abordar este tema de la urbanización amazónica.

Un elemento central de la urbanización amazónica son sus fases fragmentadas: desde la motivación de los extractivismos y las evangelizaciones hasta las dinámicas de la globalización y la modernidad, ambas dominadas por procesos de migración y relocalización. Así, siguiendo a García Canclini (1989), podemos identificar un tipo de hibridación que ocurre en el entorno urbano-rural amazónico, en el cual las culturas híbridas generadas o promovidas por el reordenamiento de lo público y lo privado en el espacio urbano y por la desterritorialización de los procesos simbólicos juegan un papel fundamental en la vida social.

\section{Modernidad, información y comunicación}

Estos procesos de desterritorialización de la vida social que se expresan en la modernidad son parte constituyente de lo que Appadurai (2001) concibe como una nueva etapa de ruptura que surge a partir de dos flujos: la expansión de los medios de comunicación y los movimientos migratorios. Estos dos flujos han conllevado a un proceso de transformación en el cual las fronteras y el aparato del Estado-nación se diluye para enmarcar a la humanidad en una etapa de posnación. 
Jaili Ivinai Buelvas Diaz, María Sirex Consuegra Díaz-Granados, David Felipe Henao Heuta, Juliana López Cuervo, John Jairo Osorio Giraldo, Laura Daniela Pardo Castellanos, Camila Peña Gómez

Teclados de cartón. Tecnologías, identidad y comunicación entre jóvenes estudiantes de la ENOSIMAR en Mitú (Vaupés), Amazonía colombiana

En este contexto, no se puede afirmar que la modernidad imprima en los sujetos una función puramente emancipadora ni enteramente disciplinada, "sino que, en definitiva, es un espacio de disputas y negociaciones simbólicas mediante el que los individuos y los grupos buscan anexar lo global a sus propias prácticas de lo moderno" (Appadurai, 2001, p. 20). Así, las dinámicas de la globalización determinan que los "Estados-nación, en tanto unidades de un sistema interactivo complejo, probablemente no sean los que vayan a arbitrar, a largo plazo, la relación entre la globalidad y la modernidad" (p. 34). Esta visión nos permite pensar sujetos complejos localizados en un entramado de comunicaciones en posiciones diversas, a veces asimétricas e irregulares. No obstante, las dinámicas de la comunicación también están asociadas a condiciones sociales, geográficas y políticas que pueden no depender directamente de los sujetos, sino de macroestructuras de la geopolítica global.

Al pensar internet y la comunicación, encontramos que los espacios online y offline no son mutuamente excluyentes y la interacción en la red responde a expectativas y regulaciones offline (Carlson, 2013). Internet no es necesariamente un espacio para esconderse ni un espacio para apagar la identidad cultural de las personas. El uso de las redes sociales e internet no es una peculiaridad de momentos fragmentados, sino un proceso cotidiano que se entrecruza con la vida offline y sus contradicciones. Esta desterritorialización -o reterritorialización en el espacio digital- de la vida cotidiana complejiza el entramado espacio-tiempo de la modernidad, incluso en sociedades con acceso irregular a las tecnologías de comunicación.

Para el caso particular del Vaupés, la comprensión del espacio como una frontera geográfica discontinua durante el siglo XX, marcada en el imaginario de las naciones por la convivencia de escasos espacios con una ocupación consolidada en el límite

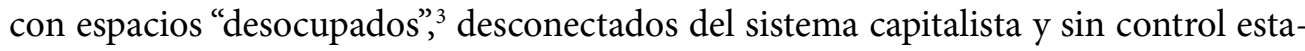
tal (Wanderley, 2018), evidenció los desafíos de incorporación del departamento a las lógicas nacionales debido a conflictos de comunicación física. Sin embargo, la lógica globalizada que se aceleró en Colombia con la transición al siglo XXI representa nuevos retos anclados en la comunicación digital. Las redes son una "nueva frontera", en las que las sociedades están representándose e identificándose en un anfiteatro global (Carlson, 2013). Así, también los esfuerzos gubernamentales de anclaje en la región se han encaminado hacia la interconexión digital.

\footnotetext{
Es preciso aclarar que, en la visión de las comunidades amazónicas y como muestran las extensas redes de intercambio y poblamiento rural, esta visión de territorio vacío es una perspectiva que cojea sin sustento en las prácticas sociales de la Amazonía, sin embargo, tal posición nortea muchas de las políticas de control y expansión de los Estados con territorios en el macrosistema amazónico.
} 
Austral Gmunicación

Volumen 9, número 2 (Diciembre de 2020): 635-675. ISSN 2313-9129

\section{Políticas e implementación de las TIC en el departamento del Vaupés (Colombia)}

Pensar en la selva amazónica y situarse en el Vaupés permite entrever las dificultades de la ejecución de las políticas y lineamientos para la llegada de internet y otras TIC en este departamento, como característica de las interfaces urbano-rurales del espacio amazónico (Alexiades y Peluso, 2016). “Es una realidad que el departamento [del Vaupés] ya inició su camino hacia el mundo tecnológico" (Martínez Acuña e Instituto amazónico de investigaciones científicas, 2014, p. 11), aseveran algunas referencias. Sin embargo, las características de ese camino han sido poco descritas.

Las innovaciones tecnológicas en el país dentro del panorama de las telecomunicaciones fueron inauguradas a través de la ley de TIC (Ley 1341/2009), expedida durante el último año de gobierno del expresidente Álvaro Uribe Vélez (2002-2010). Esta Ley le permitió al antiguo Ministerio de Comunicaciones ampliar su enfoque y denominarse como hasta la actualidad: Ministerio de Tecnologías de la Información y las Comunicaciones (MinTIC), entidad encargada de diseñar, adoptar y promover las políticas públicas, planes, programas y proyectos relacionados con lo que en adelante llamaremos "las TIC".

También, en el artículo 38, el Congreso decretó la masificación del uso de las TIC y el cierre de la brecha digital, implementando estrategias que permitieran una mayor cobertura de la conectividad, llegando así a las regiones más apartadas del país. Como propone la legislación, estos esfuerzos nacionales debían articularse con las autoridades territoriales departamentales o municipales para gestionar recursos y apoyar en este objetivo. Sin embargo, el funcionamiento de estas estrategias dependía de iniciativas que apenas comenzaron a implementarse en el Gobierno del expresidente Juan Manuel Santos (2010-2018). Las definiciones hechas en este período redundan en gran parte de las iniciativas que hoy en día siguen operando en el panorama nacional de las TIC, con el consolidado apoyo que dio el expresidente Santos a este tema en particular.

El Plan Vive Digital apostó, durante los dos períodos presidenciales de Santos, por masificar el uso de internet, generar apropiación de las tecnologías, generar empleos TIC directos e indirectos e incrementar las tasas de penetración de internet en estratos bajos y zonas rurales (Sistema Nacional de Evaluación y Gestión de Resultados, 2016, p. 4).

Esta estrategia de reducción de la brecha digital del Gobierno de Santos buscaba un correcto funcionamiento de lo que denominaban el "ecosistema digital", que regula la oferta y la demanda de TIC a partir de un despliegue de infraestructura (redes y centros de datos) y de servicios (implementados sobre las redes), además de una demanda dependiente de los usuarios que utilizan estas redes y las aplicaciones que permiten la interacción. En la estrategia del Gobierno, de la estabilidad del ecosistema digital 
Jaili Ivinai Buelvas Diaz, María Sirex Consuegra Díaz-Granados, David Felipe Henao Heuta, Juliana López Cuervo, John Jairo Osorio Giraldo, Laura Daniela Pardo Castellanos, Camila Peña Gómez

Teclados de cartón. Tecnologías, identidad y comunicación entre jóvenes estudiantes de la ENOSIMAR en Mitú (Vaupés), Amazonía colombiana

depende el acceso a contenidos que permitan el aprendizaje, la mejora en habilidades y competencias y una intensidad de uso y acceso adecuado.

\section{Acceso a las TIC en el Vaupés}

Hay que reconocer que el acceso a muchas de las TIC, hoy en día de primera necesidad para muchos, requieren principalmente de electricidad para funcionar. Esto revela el ingreso tardío de la población del Vaupés a los ecosistemas digitales: el fluido eléctrico permanente en Mitú no tiene más de quince años de instalación y aún hoy suele ser un servicio inestable. En consonancia con esto, la mayoría de los lugares diferentes a la capital del departamento siguen sin acceder a este servicio. Con ello, los esfuerzos gubernamentales se han enfocado en incrementar la conectividad de la capital.

Por parte del Ministerio se instalaron las antenas para que tengan el servicio. Anteriormente en Mitú el internet era satelital y el internet satelital es muy limitado frente a la velocidad (entre 4 megas). Hoy en día se está suministrando casi 10 megas a cada institución. ${ }^{4}$

La población del departamento del Vaupés forma parte de las zonas no interconectadas (ZNI) del país; más del 70\% de sedes educativas no tienen electricidad (Consejo Nacional de Política Económica y Social, 2020). Esta carencia del servicio de energía ha sido una limitante para el acceso, uso y apropiación de las TIC. Según el Documento CONPES 3988, la ausencia de programas se debe a la inexistencia de conexiones estables de internet o electricidad. Por supuesto, ante este factor no es de extrañar que las cifras de implementación de estos programas TIC no muestren los resultados esperados dentro del panorama nacional y, en cambio, sí recalcan la dificultad y los retos de la implementación de este tipo de tecnologías en lugares tan apartados del país.

Esta situación es reconocida también en el contexto local, como nos manifestó una profesora de la ENOSIMAR: "Acá hay niños que llegan a [la ENOSIMAR a cursar grado] sexto, porque hicieron su primaria en comunidades rurales y llegan acá y no saben prender un computador, en esas comunidades no hay la posibilidad de un acceso a eso". ${ }^{5}$ Así, las condiciones de movilidad de los estudiantes de las escuelas de Mitú dificultan una continuidad en la instalación de habilidades tecnológicas, retardando ese proceso en comparación con otros lugares con acceso a electricidad e internet.

A pesar de la permanencia del servicio, en Mitú el costo de la energía es sensiblemente más alto que en otras regiones del país. Debido a que el departamento no participa de las redes eléctricas nacionales por barreras geográficas, el funcionamiento de las generadoras eléctricas es exclusivamente termogénico y se realiza con combustible diésel, que debe ser transportado desde San José del Guaviare a Mitú por vía aérea y

4 Entrevista realizada el 5 de diciembre de 2019 a un funcionario público departamental en su despacho en Mitú.

5 Entrevista realizada el 24 de marzo de 2020 a una profesora en su domicilio en Mitú. 
Austral Comunicación

Volumen 9, número 2 (Diciembre de 2020): 635-675. ISSN 2313-9129

desde allí a los dos otros municipios del departamento: Carurú y Taraira; esto hace que el costo del combustible y del transporte sea alto; y el proceso, bastante problemático. En estos últimos dos municipios el fluido eléctrico apenas se distribuye en determinadas horas al día.

La situación ha evidenciado la necesidad de implementar proyectos de generación de electricidad con fuentes energéticas alternativas, como, por ejemplo, las que se han venido implementando a través de la instalación de paneles solares (soluciones fotovoltaicas), que, aunque no brindan una capacidad muy grande en suministro energético, sí han permitido que hogares e instituciones accedan por primera vez a este servicio.

En 2019 se implementaron a través del MinTIC las Fichas Departamentales y Oferta Institucional, que muestran indicadores por departamento relacionados con el acceso a las TIC.

La Tabla 1 presenta algunas de estas estadísticas que encontramos relevantes. En una comparación, se evidencia que las tecnologías relacionadas con las comunicaciones y la informacion han avanzado en el pais y se han ido extendiendo en, por ejemplo, casi la totalidadidederes nificativamente diferentes en el departamento del Vaupés, que, tiene grandes retos para el acceso a estas teccidal degagarga promedio de esusciptores y asequibles. Porcentaje de hogares con computador, portátil o tableta $\quad 27,10 \% \quad 68,90 \%$

\begin{tabular}{|c|c|c|}
\hline Porcentaje de personas con teléfono celular & $45,80 \%$ & $84,50 \%$ \\
\hline \multicolumn{2}{|c|}{ 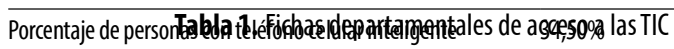 } & $76,50 \%$ \\
\hline Porcentaje de hogares con televisión & $72,50 \%$ & $97,30 \%$ \\
\hline Accidentes 0 incidentes no viales & $3,10 \%$ & $3,40 \%$ \\
\hline Ambiente & $2,10 \%$ & $2,60 \%$ \\
\hline DDHH & $2,10 \%$ & \\
\hline Fuerzas Armadas & $2,10 \%$ & $0,90 \%$ \\
\hline Judiciales & & $1,70 \%$ \\
\hline
\end{tabular}


Jaili Ivinai Buelvas Diaz, María Sirex Consuegra Díaz-Granados, David Felipe Henao Heuta, Juliana López Cuervo, John Jairo Osorio Giraldo, Laura Daniela Pardo Castellanos, Camila Peña Gómez

Teclados de cartón. Tecnologías, identidad y comunicación entre jóvenes estudiantes de la ENOSIMAR en Mitú (Vaupés), Amazonía colombiana

Sin embargo, es de resaltar el progresivo uso de celulares inteligentes que ofrecen una variada gama de posibilidades para acceder a las TIC y que, en la mayoría de los casos, han permitido el acceso a internet de manera más rápida sin necesidad de tener un computador, que usualmente es percibido como más complejo de usar y más costoso. Tanto el uso de celulares como el de la televisión son el acercamiento más próximo a la tecnología en la vida cotidiana de la población vaupense.

Situándonos en el contexto educativo del Vaupés, al cual llegan gran parte de estas iniciativas TIC, durante la realización de los talleres con los jóvenes de la ENOSIMAR les preguntamos sobre cuáles dispositivos utilizaban o conocían. En este se les pidió que plasmaran en unas carteleras lo que entendían por los conceptos de tecnología, información y comunicación. Esto nos permitió explorar algunas de las ideas previas que los jóvenes de la ENOSIMAR tenían sobre estos conceptos y conocer cómo era su aproximación a las tecnologías. Un aspecto importante es que durante esta sesión algunos de los chicos hicieron referencia, bajo la categoría de tecnología, a objetos de uso tradicional en las comunidades, como el matafrío (herramienta que se usa para exprimir la yuca brava), señalando que este era un objeto que se había creado con la intención de cumplir una función y hasta el momento seguía siendo la herramienta más práctica para solucionar ese problema: extraer el veneno (manicuera) de la yuca brava.

Además, otros de los chicos señalaron a la carta como un ejemplo asociado a los conceptos de comunicación, información y tecnología, pues comunicaba información a través de un invento tecnológico como la escritura. En general, estos términos fueron asociados a los celulares y computadores, así como a las aplicaciones móviles (redes sociales, correo electrónico) de los smartphones. Esto demuestra que entre los jóvenes que participaron del taller había una noción básica de las tecnologías como respuestas creativas para la solución de un problema, es decir, la aplicación de saberes y conocimientos para la creación o invención, a partir de la utilización de diversos recursos, de herramientas que cumplen una función práctica, respondiendo a una necesidad identificada y concreta.

Ahora bien, uno de los aspectos clave que logramos identificar en este taller y confirmar en los talleres posteriores fue que, para la mayoría de los jóvenes, particularmente de los internos de la ENOSIMAR, su primer contacto con las TIC había sido tardío, predominantemente al iniciar el bachillerato, y que en sus hogares nunca habían hecho uso de aparatos como un computador o tableta, especialmente los que provenían de las comunidades rurales. Esto supone, a todas luces, una posición asimétrica y de desigualdad frente a los jóvenes de los contextos urbanos de otras regiones del centro del país y, evidentemente, demuestra los vacíos del sistema educativo en Colombia a la hora de encarar esta problemática. Sin embargo, cada vez es más común que, con la instalación de "soluciones fotovoltaicas" en las comunidades, las personas que tienen 
Austral Comunicación

Volumen 9, número 2 (Diciembre de 2020): 635-675. ISSN 2313-9129

acceso a la electricidad a través de la energía solar adquieran dispositivos móviles de comunicación (smartphones) u otros aparatos electrónicos como los televisores. Esto no solo significa que su acceso al uso de las tecnologías se da como consumidores o receptores, sino que son ingresados en una lógica de mercado que interfiere en las dinámicas locales y los convierte en nuevos clientes para los proveedores de servicios de telecomunicación (telefonía, internet, televisión satelital, etc.). Ante esto, resaltaron la centralidad del celular en sus interacciones tecnológicas y manifestaron que los utilizaban casi exclusivamente cuando estaban en Mitú para escuchar música y usar las redes sociales. El elemento que más asociaron a cada uno de estos tres conceptos (tecnología, información y comunicación) fue también el celular.

Una de las profesoras entrevistadas nos relató su experiencia antes de llegar a trabajar a Mitú, cuando era profesora de informática, hacía 7 años, en el colegio Monfort ubicado en Yavaraté, zona fronteriza del departamento del Vaupés con Brasil. La profesora comparó la situación de este internado, ubicado en una comunidad rural muy alejada de la capital, con su experiencia al llegar a la ENOSIMAR. Su narrativa revela la percepción de que si bien en el actual colegio no cuenta con las mejores condiciones para el desarrollo de su clase, la situación sí es mucho menos compleja que en el anterior colegio donde trabajó. ${ }^{6}$

A partir de esto, podemos hablar de que la brecha digital al interior del departamento del Vaupés toma connotaciones dramáticas si comparamos las áreas rurales con la capital, ya que la mayoría de los programas que hacen frente al acceso de las TIC se concentran y focalizan en Mitú, mientras que en el resto de lugares y comunidades del departamento todavía no cuentan con el acceso a estas tecnologías, o si las tienen, encuentran grandes deficiencias en la calidad del servicio y su uso es muy esporádico, casi nulo. Esto conlleva a que muchos jóvenes tengan sus primeras experiencias de contacto con las TIC solo al llegar a Mitú, como es el caso de los niños que realizaron su primaria en una comunidad rural y llegan aquí para cursar su bachillerato.

Por otro lado, la razón fundamental dada por los funcionarios del municipio y del departamento es que, a pesar de los esfuerzos estatales, no se ha logrado tener conectividad en el departamento, ya que no existen los suficientes recursos para garantizarla: los costos e inversiones para adecuar las redes e infraestructura son bastante altos. Pero el proyecto investigativo ha evidenciado también que los pocos programas implementados en Mitú y en otros municipios del departamento muestran debilidades en su operación y continuidad.

\section{Programas TIC implementados en el Vaupés}

Entrevista realizada el 24 de marzo de 2020 a una profesora en su domicilio en Mitú. 
Jaili Ivinai Buelvas Diaz, María Sirex Consuegra Díaz-Granados, David Felipe Henao Heuta, Juliana López Cuervo, John Jairo Osorio Giraldo, Laura Daniela Pardo Castellanos, Camila Peña Gómez

Teclados de cartón. Tecnologías, identidad y comunicación entre jóvenes estudiantes de la ENOSIMAR en Mitú (Vaupés), Amazonía colombiana

En general, el ingreso de tecnologías digitales a este territorio es muy tardío (aunque debe reconocerse que también lo fue el de la mayoría de las regiones del país), su consolidación presenta mayores desafíos derivados de conflictos étnicos, sociales, geopolíticos y comerciales. "Internet no teníamos nada, después, con el tiempo comenzó un poquito el internet, pero muy difícil. La conectividad aquí es muy mala, y actualmente sigue siendo mala, es de imaginarse hace 15 años o más cómo sería"?

El principal programa del MinTIC que se ha venido ejecutando en el Vaupés es el Plan Nacional de Conectividad de Alta Velocidad que busca traer conectividad a las zonas más apartadas de Colombia, priorizando entre ellas la Amazonía, la Orinoquia y el Pacífico. Este programa no solo lleva internet, sino toda la oferta de proyectos relacionados con las TIC para las comunidades e instituciones beneficiarias.

Desde el nivel central se planean muchas acciones y se definen metas. Las cifras del Gobierno frente a las líneas que maneja el MinTIC responden favorablemente, pero, al entrar en detalle, se puede evidenciar que en lugares como el Vaupés los procesos geopolíticos de la interfaz amazónica urbano-rural, conjugada con la presencia diferenciada del Estado colombiano, exacerban el abanico de dificultades que contribuyen a que la ejecución de los programas existentes tenga semejantes falencias. En concordancia con lo que Robins y Webster (1988) postulan, el contexto del Vaupés otorga herramientas para la construcción de una visión crítica que no concibe a la tecnología como un proceso neutral. Analizar desde esta postura la incursión de los programas de TIC implementados en el Vaupés nos permite entender su relación con los sujetos indígenas como procesos anclados a los contextos políticos y sociales particulares de la modernidad neoliberal.

\section{Computadores para educar}

En el marco de este interés nacional por competir globalmente a través del uso de las TIC, entidades de carácter nacional y público, como la Presidencia de la República, el Ministerio de las TIC, el Ministerio de Educación Nacional, el Fondo TIC y el Servicio Nacional de Aprendizaje (SENA) se asociaron y posibilitaron la creación del programa "Computadores para Educar", que busca promover el acceso, uso y apropiación equitativa y sostenible de las TIC mediante la entrega de equipos de cómputo u otras herramientas tecnológicas como tabletas.

Creado entre 2000 y 2001, ha sido presentado por el Gobierno como un programa sostenible con una prospección cargada de optimismo tecnológico (Buckingham 2008; López 2008). Según la visión institucional: "En 2025 Computadores para Educar habrá contribuido a que Colombia sea la más educada con el apoyo de las TIC, permi-

Entrevista realizada el 24 de marzo de 2020 a un profesor en su domicilio adjunto a la ENOSIMAR. 
Austral Comunicación

Volumen 9, número 2 (Diciembre de 2020): 635-675. ISSN 2313-9129

tiendo que cada niño colombiano acceda a educación de clase mundial, que lo prepare para el mundo" (Ministerio de Tecnologías de la Información y las Comunicaciones, 2020, sec. Visión).

Una de las mayores críticas al programa por parte de los educadores y funcionarios entrevistados -que, sin embargo, ensancha los pechos de los funcionarios nacionales como un impacto ambiental positivo del programa- es la estrategia de recolectar computadores dados de baja por empresas públicas y privadas para reacondicionarlos y entregarlos a escuelas y colegios públicos. "Los computadores para educar son reciclados de reciclados, por eso pierden la vida útil muy rápido y cuando se dañan ya sale más caro el arreglo". Esta labor de reacondicionamiento, al parecer, no resulta eficiente en la práctica, ya que la vida útil de estos equipos se reduce por cada mantenimiento y estos se vuelven obsoletos por las innovaciones a las que permanentemente se enfrenta el campo de las tecnologías de la información y comunicación. El que sean computadores de tecnologías antiguas impiden su correcto uso y disfrute, más cuando se busca acceder a las redes de internet o contenidos en línea. Tanto funcionarios ligados a la política de TIC en el Vaupés como profesores de la ENOSIMAR manifiestan las falencias operativas del programa. "[...] antes, hace como dos años, sí venían unos del ministerio, eran unos técnicos, que ellos venían a hacerle mantenimiento a los equipos, pero este año no. Y las tablets están ahí, que son como 45, no todas sirven, pero sí alcanzan de a una para cada niño, alcanzan más que los computadores".

\section{La cuestión del acceso}

En los contextos referentes a particularidades étnicas, algunos investigadores apuntan a una carencia en la reflexión académica sobre las tecnologías de medios digitales. Esto ha sido así debido a la tendencia a no encontrarlas demasiado beneficiosas en la vida de los jóvenes etnizados y racializados por las políticas multiculturalistas. Esta observación no necesariamente está relacionada con encontrar la tecnología como un factor negativo para el desarrollo de los jóvenes indígenas, sino del reconocimiento de las consecuencias innegables de la constante desigualdad en las estructuras profundas de la economía y el acceso a las tecnologías de información al interior de las lógicas nacionales (Guins y Sandoval, 2008). Ahora bien, la abundancia de formas en las que los jóvenes indígenas hoy en día se apropian con éxito de las herramientas de los medios digitales para incurrir en una esfera pública digital es cada vez más prominente. Así, las limitaciones de tipo social, alimentadas por las asimetrías a las que los grupos étnicos se enfrentan en la cotidianidad, se conjugan con experiencias de resistencia

\footnotetext{
8 Entrevista realizada el 4 de diciembre de 2019 a un funcionario público municipal en su despacho en la sede de la alcaldía de Mitú.

9 Entrevista realizada el 26 de marzo de 2020 a un profesor en su domicilio en la ciudad de Mitú.
} 
Jaili Ivinai Buelvas Diaz, María Sirex Consuegra Díaz-Granados, David Felipe Henao Heuta, Juliana López Cuervo, John Jairo Osorio Giraldo, Laura Daniela Pardo Castellanos, Camila Peña Gómez

Teclados de cartón. Tecnologías, identidad y comunicación entre jóvenes estudiantes de la ENOSIMAR en Mitú (Vaupés), Amazonía colombiana

en las que los jóvenes de comunidades étnicas se apropian para satisfacer sus propias preocupaciones y agendas generacionales.

En última instancia, debemos ver esto no solo como un problema de los indígenas, sino como un conflicto que involucra a nuestra sociedad en general, dado que las tecnologías de la información interactúan con sujetos imbricados en redes de poder que potencialmente son replicadas en sus usos tecnológicos. En este sentido, si bien las cuestiones sobre el acceso a los medios digitales ocupan buena parte del abanico de interrogantes, también lo hacen asuntos como la integridad cultural, la sostenibilidad ambiental y las relaciones entre comunidades rurales y la sociedad nacional.

El primer obstáculo en la investigación y discusión sobre la desigualdad de la información -o, como ha sido llamada, "brecha digital"- son las dificultades que se han presentado al definir el acceso. El concepto de "acceso" ha postulado varios contextos cotidianos de uso y ha sido poco definido, sin reconocer el hecho de que hay muchos significados divergentes en juego. El significado de simplemente tener un computador y una conexión de red es el más común en uso hoy en día. Sin embargo, como exponen Van Dijk (1999) y Van Dijk y Hacker (2003), el concepto se subdivide en cuatro tipos de acceso sucesivos, relativos a los tipos de barreras de acceso y al tipo de acceso que restringen: 1) la falta de experiencia digital causada por falta de interés, ansiedad informática y falta de atractivo de la nueva tecnología, que restringiría el acceso mental; 2) la falta de computadores y conexiones de red, que desemboca en una falta de acceso material; 3) La ausencia de habilidades digitales causadas por una poca facilidad de uso de las herramientas y una educación o red de apoyos inadecuados, que restringe el acceso a habilidades; $y, 4)$ la carencia de oportunidades de uso significativas que representen una ventaja de uso de las TIC, lo que soterra el acceso de uso.

Las comunidades étnicas rurales no se ausentan de estos cuatro componentes del acceso. En ellas se evidencian, en múltiples niveles, que atraviesan tanto las limitaciones de infraestructura y de lógicas de uso como las de formación de capacidades técnicas, todo esto en conjunción con sus propias preocupaciones y agendas en defensa de sus derechos étnicos, como en las particularidades cotidianas que representa una cosmovisión no occidental.

En este sentido, se hace cada vez más evidente que la "brecha digital" atraviesa elementos que no solo atienden cuestiones de infraestructura tecnológica, sino de dispositivos sociales.

[...] el acceso significativo a las TIC comprende mucho más que simplemente proporcionar computadoras y conexiones a Internet. Más bien, el acceso a las TIC está integrado en una compleja serie de factores que abarcan recursos y relaciones físicas, digitales, humanas y sociales. El contenido y el lenguaje, la alfabetización y la educación, y las estructuras 
Austral Comunicación

Volumen 9, número 2 (Diciembre de 2020): 635-675. ISSN 2313-9129

comunitarias e institucionales deben tenerse en cuenta para proporcionar un acceso significativo a las nuevas tecnologías (Warschauer, 2004, p. 6). ${ }^{10}$

Una de las aristas del problema es que gran parte de la programación educativa en el área de informática se basa en el pensamiento convencional sobre la educación; además, si los computadores van a escuelas o instituciones gubernamentales, su uso estará sujeto a estándares y políticas escolares, no necesariamente comunitarias o étnicas. Esto es especialmente dramático cuando el único contexto de acceso a la tecnología de los jóvenes indígenas es la escuela. Ahora bien, no es solamente que existe una desconexión entre lo enseñado en las aulas y las comunidades indígenas del Vaupés, sino que la continuidad de los procesos de aprendizaje se interrumpe una vez que ellos retornan a sus comunidades, donde no cuentan con las condiciones necesarias para el uso de TIC (equipos, energía, internet): "Dentro de la clase, los muchachos aprenden y hacen buenos proyectos. Después de que salen para sus casas o comunidades, el acercamiento es nulo por la falta de dispositivos". ${ }^{11}$

Como muestran las investigaciones, los procesos políticos que promueven el uso de las TIC en las escuelas alrededor del mundo y también una parte considerable de los educadores consideran que los computadores e internet empoderan a los estudiantes (Cabrol y Severin, 2010; Evoh, 2007; Majoka, Fazal, y Khan, 2013; Mikre, 2011; Urrutia, Urrutia y Chiluisa, 2017). En términos del concepto de que los computadores empoderan a las personas, inclusive se encuentran relaciones estadísticas entre el tiempo de uso de computadores y el buen rendimiento académico (Jackson, Zhao, Kolenic, Fitzgerald, Harold, Von Eye, 2008). Sin embargo, cuando el único espacio de acceso al mundo digital son las escuelas, se exacerban inequidades que se han enquistado en nuestra sociedad. La mayoría de los computadores y las redes escolares poseen filtros muy estrictos y limitaciones de uso, esto se traduce en que los estudiantes a menudo encuentran proscrito el acceso a muchos sitios web, incluidos algunos bastante inocuos, especialmente las redes sociales y espacios de interacción social en el mundo digital. Cuando se compara con estudiantes en las mismas condiciones escolares, pero con acceso a dispositivos en sus casas que les brindan un acceso más libre, se evidencia que los estudiantes indígenas están limitados por las políticas de aquellos que proporcionan acceso y alojan los sistemas informáticos (López, 2008). Este es el caso de muchos estudiantes indígenas en cuyas comunidades las TIC se encuentran vedadas por las cuatro limitaciones en el acceso identificadas por Van Dijk (1999). Así, algunos de los programas que intentan disminuir la brecha digital no necesariamente empoderan

${ }_{10}$ Traducción propia.

${ }^{11}$ Entrevista realizada el 24 de marzo de 2020 a una profesora en su domicilio adjunto a la ENOSIMAR. 
Jaili Ivinai Buelvas Diaz, María Sirex Consuegra Díaz-Granados, David Felipe Henao Heuta, Juliana López Cuervo, John Jairo Osorio Giraldo, Laura Daniela Pardo Castellanos, Camila Peña Gómez

Teclados de cartón. Tecnologías, identidad y comunicación entre jóvenes estudiantes de la ENOSIMAR en Mitú (Vaupés), Amazonía colombiana

a los estudiantes individualmente, porque están inhibidos por restricciones competentes con los diversos tipos de acceso.

\section{Contenidos digitales y aplicaciones}

En el caso de las juventudes indígenas escolarizadas, la brecha digital atraviesa las contradicciones del sistema educativo nacional en las comunidades locales, de manera que la tecnología sea accesible, esto es, atractiva, presente en medios físicos y de infraestructura nacional, acompañada de procesos de formación de habilidades y útil a los contextos locales. Esto requiere, como señala López (2008), una reflexión interesante sobre el paradigma operativo de la educación para indígenas, a fin de comprender completamente lo que se requiere en aras de brindar a los jóvenes las herramientas críticas para que no solo reproduzcan los supuestos del sistema hegemónico, sino para que también sean partícipes de una pedagogía cultural y localmente relevante. Esto no solo alude al supuesto del determinismo informático o a una mirada técnica sobre las TIC, sino a que, como hemos definido, el acceso también pasa por oportunidades de uso significativas, sin las cuales cualquier inversión hecha en infraestructura no garantizará el cierre de la llamada "brecha digital".

En materia de reducción de la brecha digital, los programas gubernamentales y la discusión sobre la tecnología para las comunidades desatendidas se basa en la segunda definición de "acceso" -el acceso material-, pero rara vez se contextualiza en términos de sabiduría y conocimiento étnico. En general, carecen de una pedagogía que incorpore al arte, la ecología, los saberes del monte o los vínculos de comunidad. Las políticas públicas dedicadas a mermar la brecha digital desconocen con una pasmosa negligencia las condiciones sociales del país, desconociendo la preocupación de que estos esfuerzos realmente tengan un efecto y una utilidad en las lógicas locales. En una de las entrevistas, la profesora de informática nos contó sobre la vez que se enfrentó a un joven que se comportaba de manera reacia en su clase. Un día, este la interpeló y le preguntó: "Profe, y esto para qué me va a servir a mí en la comunidad". ${ }^{12}$ En un intento por mantener la motivación del joven en la clase, la profesora se respaldó en la importancia de saber informática en caso de que él decidiera estudiar una carrera en el SENA o algo similar después del colegio. Sin embargo, esta respuesta no corresponde al cuestionamiento planteado desde el punto de vista de la comunidad, sino que se relaciona únicamente con la realización del proyecto de vida individual de este joven. "El Ministerio tiene programas y aplicaciones y todo eso, entonces se deben crear apli-

${ }_{12}$ Entrevista realizada el 3 de marzo de 2020 a una profesora en la ENOSIMAR. 
Austral Comunicación

Volumen 9, número 2 (Diciembre de 2020): 635-675. ISSN 2313-9129

caciones para fortalecer esa cultura, esa tradición de estas comunidades, empezar a implementar eso desde la escuela". ${ }^{13}$

Esto se evidencia de forma contundente en la opinión de los profesores sobre los contenidos a los que los equipos tienen acceso. Como lo establecen los lineamientos del Ministerio de Educación Nacional, las estrategias de formación y capacitación a instituciones educativas, docentes y estudiantes se hace por medio del uso de las TIC. Estos contenidos digitales se vuelven importantes en la medida en que muchos vienen preinstalados en los computadores o tabletas del programa Computadores para Educar y su uso puede no requerir de conexión a internet. Estos programas, plataformas, aplicaciones y herramientas buscan enriquecer el ejercicio pedagógico en las aulas para todas las áreas de conocimiento y los diferentes actores del contexto educativo, y tienen la intención de prestar especial énfasis en brindar contenidos entretenidos a través de la interacción y uso de las TIC, buscando afianzar la apropiación de estas herramientas tecnológicas en los usuarios de estos contenidos. Sin embargo, la frustración principal ocurre cuando los docentes se ven incapaces de replicar y extender los beneficios de estos programas a los jóvenes debido a las limitaciones de los contextos locales y a la desconexión de los contenidos padronizados y pensados desde los centros de poder nacional con las afinidades regionales y locales de los estudiantes.

\section{Espacios de conectividad}

En la implementación de programas de acceso material, una de las iniciativas de mayor alcance ha sido el Plan Vive Digital, con la instalación de Puntos y Kioskos Vive Digital. En el Departamento del Vaupés, fue posible su instalación a través del Programa Nacional de Alta Conectividad y ha gozado de buena acogida entre la población. Así, también los funcionarios públicos enfocan y resaltan el hecho de que el programa ha permitido el ingreso de espacios públicos de acceso a la red en lugares en los que previamente a la existencia del programa la existencia de internet era nula. " $\mathrm{La}$ llegada de internet es un logro importante, desde el 2012 se viene escuchando que iban a llegar las antenas para el internet y no había sido posible ver eso". ${ }^{14}$

\footnotetext{
13 Opinión de la misma profesora, entrevistada el 3 de marzo de 2020.

14 Entrevista realizada el 5 de diciembre de 2019 a un funcionario público departamental en su despacho en Mitú.
} 
Los Puntos Vive Digital (PVD) consisten en la habilitación de centros de acceso a internet en cabeceras municipales de estratos 1 y $2,{ }^{15}$ principalmente. El centro consta de computadores portátiles, diademas, televisores, monitores interactivos, salas para formación y conferencias, consola de videojuegos e impresora multifuncional. Ofrece capacitaciones y contenidos digitales preinstalados especializados para las comunidades educativas (docentes y estudiantes). Los Kioskos Vive Digital (KVD), si bien también consistían en generar puntos de acceso comunitario a internet, iban dirigidos a centros poblados ubicados en veredas o corregimientos; a veces, el KVD era el único punto de acceso a internet en estos territorios rurales.

Ambas iniciativas contaban con jornadas de capacitación, equipos de entretenimiento, acceso a contenidos y aplicaciones, entre otras actividades complementarias. A grandes rasgos, este programa resultó de gran impacto nacional. Sobresale que su existencia permitió por primera vez el acceso a internet en muchos municipios y corregimientos y, con ello, la realización de actividades escolares, usos de entretenimiento -como ver vídeos, escuchar música y jugar-, realización de trámites en línea con el Estado, búsqueda de empleo, solicitud de citas para salud, transacciones comerciales, comunicación y participación a través de correo electrónico, redes sociales, etcétera.

Desde mediados de 2018, viene funcionando la estrategia de Puntos Vive Digital en el departamento del Vaupés, primero en el municipio de Carurú y meses después en Taraira. En Mitú se tienen proyectados dos Puntos Vive Digital que, a finales de 2019, se estaban terminando de dotar. ${ }^{16}$ La implementación de estos programas debe garantizar la continuidad y sostenibilidad en el tiempo y esta ha sido una de las principales críticas del Gobierno de Iván Duque (2018-2022) sobre estos programas, ya que muchos de los procesos de contratación comenzaron a finalizar y no contaban con financiación para asegurar su continuidad en el primer año de su Gobierno. Estas dificultades minan no solo la continuidad de la operación de estos puntos, sino también su

\footnotetext{
15 Debe recordarse que, a diferencia de la mayoría de los países del mundo, el Gobierno colombiano ha diseñado un sistema de segmentación poblacional basado en los sitios de vivienda. Las ciudades en Colombia se fragmentan en múltiples zonas que se identifican en una escala social. La escala tiene 6 "estratos" identificados por su número. En los más bajos -el 1, 2 y 3 - viven los ciudadanos de menores recursos, los cuales reciben subsidios en los servicios públicos (agua, gas, luz); en los más altos -el 5 y 6-, quienes pagan esas ayudas con facturas superiores a su consumo. Este sistema, que por un lado subsidia a los hogares pobres, también promueve la espacialización de la riqueza en Colombia. El modelo de estratificación socieconómica "es la clasificación de los inmuebles residenciales de un municipio, que se hace en atención a los factores y procedimientos que determina la ley" (El Congreso de Colombia 1994, artículo 14) se basa en el precepto de que "estratificar con base en las características de las viviendas y su entorno urbano o rural es una opción metodológica fundamentada en que el significante vivienda-entorno expresa un modo socioeconómico de vida" (Departamento Administrativo Nacional de Estadistica, s.f.).

${ }^{16}$ Uno de estos Puntos en Mitú será Punto Vive Digital Plus, a cargo de la Gobernación, cuya edificación ya está hecha. MinTIC dota al Vive Digital Plus de computadores de mesa, computadores portátiles, zona de juegos como X-box, área de entretenimiento y un área de instrucción o capacitación y el valor agregado de los equipos de producción de contenidos audiovisuales, como cabina de radio y televisión. El otro punto que se ubicará en Mitú es el Punto Digital Tipo B, a cargo de la Alcaldía. Este punto quedará cerca del SENA, con características más sencillas que habilitan una velocidad de conexión superior de $6 \mathrm{MB}$, en comparación con los tipos $\mathrm{C}$ y $\mathrm{D}$, que tienen una velocidad de $4 \mathrm{MB}$.
} 
Austral Comunicación

Volumen 9, número 2 (Diciembre de 2020): 635-675. ISSN 2313-9129

expansión, perdiéndose en el devenir de las administraciones, en la burocracia estatal, en las contrataciones con operadores tercerizados y en la corrupción. Frente a esto, nos cuentan que, en la actualidad, en las contrataciones para la prestación de los servicios de las TIC se prioriza la instalación de infraestructura, pues facilita la desviación de los recursos y se deja de lado el componente de capacitación en el uso de las tecnologías instaladas. En esta maraña de reorganizaciones y dificultades de financiación, cada vez se complica más la efectiva llegada a las poblaciones rurales con esta política, la mejora de aspectos técnicos como la velocidad de internet y la construcción de contenidos y usos más acordes con las realidades regionales. Todo esto genera la percepción en los usuarios y comunidades de que el potencial de Vive Digital está siendo ampliamente desperdiciado. Así, la vocación formadora del programa no consigue promover los niveles de acceso en materia de herramientas y de usos (Van Dijk 1999; Van Dijk y Hacker 2003), como se evidencia en las opiniones de los profesores, quienes, a su juicio, encuentran que los jóvenes "les dan un mal uso a los puntos Vive Digital en lugar de aprovecharlos en lo que los tienen que aprovechar". ${ }^{17}$

\section{Zonas wifi}

En la actualidad, el municipio de Mitú cuenta con dos zonas wifi, las cuales, si bien no proporcionan dispositivos para el acceso a internet, facilitan la conexión en espacios públicos para que los usuarios que tengan dispositivos propios accedan de manera gratuita a internet. Están distribuidas en dos zonas relativamente distantes y estratégicas de la ciudad, pensando asegurar una mejor redistribución del servicio. Una se ubica en el Parque Central Santander, que dispone de bancas de cemento alrededor y con fuentes de alimentación de energía, facilitando la conectividad y la carga de los dispositivos. Varias personas se encuentran siempre en los alrededores del parque usando la red hasta altas horas de la noche, ya que este es el mejor momento para asegurar la calidad de la señal y porque, en ocasiones, el extenuante sol del día hace insoportable la permanencia allí. Además, en horario diurno, acceder a internet por este medio y cualquier otro es prácticamente imposible por el colapso de la red.

La otra zona wifi en Mitú se localiza en la Biblioteca Virtual Shaddai, cuyas instalaciones la conforman un avión que se encuentra en desuso y en cuyo interior hay una sala dotada con computadores, tabletas, etc. Para usarla como zona wifi solo es necesaria la clave de acceso para poder conectarse y tener internet gratis, por esta razón, alrededor del avión se sientan algunas personas ensimismadas en sus celulares debajo de los pocos árboles que dan sombra.

${ }_{17}$ Entrevista realizada el 24 de marzo de 2020 a una profesora en su domicilio en Mitú. 
Jaili Ivinai Buelvas Diaz, María Sirex Consuegra Díaz-Granados, David Felipe Henao Heuta, Juliana López Cuervo, John Jairo Osorio Giraldo, Laura Daniela Pardo Castellanos, Camila Peña Gómez

Teclados de cartón. Tecnologías, identidad y comunicación entre jóvenes estudiantes de la ENOSIMAR en Mitú (Vaupés), Amazonía colombiana

Si bien las zonas wifi son de uso frecuente, suelen tener pérdidas de velocidad debido a la cantidad de usuarios que se conectan a ellas; las personas lo saben y buscan horarios en los que no se conecten tantas personas a la vez, razón por la cual se ve gente a las 12 de la noche intentando descargar o subir algún archivo con el internet gratis que ofrece este programa.

\section{Instituciones públicas conectadas}

En Mitú, a finales de 2019, había veinte instituciones públicas conectadas y que actualmente cuentan con internet, como la Alcaldía, la Gobernación, el Hospital San Antonio, el Batallón, la Policía, la Defensoría del Pueblo, el SENA y las tres instituciones educativas: la ENOSIMAR, el Colegio Inayá y el Colegio José Eustasio Rivera. Analizar el impacto de esta política dentro del panorama municipal, departamental y educativo en el Vaupés nos revela que el uso exclusivo de wifi -la cantidad de señales que pueden estar entrando y saliendo en la misma institución- puede afectar la estabilidad de la señal, aunado a las distancias limitadas del rango de alcance del wifi. Una de las propuestas de mejora de este sistema consiste en acoplar mejor las redes internas, conectando puertos de red y creando redes internas LAN a través de cableado, lo que permitiría que las condiciones del servicio sean más eficientes. No obstante, corresponde a las instituciones territoriales que reciben el servicio garantizar las condiciones de infraestructura interna. Lamentablemente, no se ha podido consolidar una apropiación de los recursos que se han venido ofreciendo institucionalmente, dado que no cuentan con un área técnica que pueda hacerles mantenimiento y adaptaciones ni con los recursos presupuestales para garantizar la contratación externa de este servicio.

\section{Capacitaciones y estrategias pedagógicas desde las TIC}

En el caso del Vaupés, el MinTIC no desconoce totalmente que dotar de infraestructura a un ecosistema digital no es suficiente para el acceso y uso de estas herramientas (Van Dijk y Hacker, 2003; Warschauer, 2004), es por eso que a los usuarios que demandan estos servicios se les brindan capacitaciones que permitan interactuar con las herramientas TIC. Principalmente, son las entidades educativas quienes se benefician de estas, especialmente los docentes para que puedan replicar estos saberes a los alumnos. Sin embargo, el MinTIC se ha mostrado negligente en garantizar el acceso por medio de capacitación de calidad. Algunos docentes entrevistados refieren que las capacitaciones, cursos, diplomados y demás estrategias de formación recibidas han sido insuficientes y "muy por encima". ${ }^{18}$

${ }_{18}$ Entrevista realizada el 24 de marzo de 2020 a un profesor en su domicilio. 
Para muchos docentes, estas capacitaciones no fueron suficientes, y de no ser por la iniciativa autónoma y su interacción con los equipos brindados, carecerían de las experiencias de uso de las TIC que aportan innovación en las apuestas pedagógicas de las clases. "En la parte pedagógica ha sido muy bueno, porque prácticamente es salir de la rutina del tablero-tiza". ${ }^{19}$ Los mismos docentes afirman que estas apuestas pedagógicas ayudan en sus clases y que tratan de utilizar las tecnologías disponibles dentro de las áreas que manejan, sin embargo, aplicar las TIC es más fácil en algunas áreas que en otras y el desconocimiento de estas impide implementar estas herramientas digitales en todas las áreas del conocimiento. Solicitan una mejor frecuencia en las capacitaciones, en especial para los docentes del área de tecnología e informática. Algunos docentes de distintas áreas manifiestan un desconocimiento de estrategias pedagógicas que les permitan aplicar las TIC a sus salas de aula:

En mis clases de matemática y física la estoy tratando de implementar. Busco los recursos en internet, luego recopilo la info que necesito dictarles a ellos a través de videos bajados de YouTube, de la página del Ministerio, de Colombia Aprende y todas esas cosas. ${ }^{20}$

Sin embargo, como sus experiencias lo demuestran, el uso de las TIC se limita a la planeación de las aulas, sin incidir directamente en los estilos pedagógicos ni en la interacción de los estudiantes con estas tecnologías.

Muchos profesores, incluso, encuentran la complicación de adaptarse a un sistema global cambiante que ha transformado su relación con los dispositivos y la comunicación (Buckingham, 2008; Castells, 2013; Herring, 2008). Encontramos que las lógicas de prohibicionismo comunicacional y el apego a estrategias educativas que hoy parecen obsoletas los colocan en la dicotomía entre asumir el papel de educadores desde la pedagogía en la que se formaron -probablemente con anterioridad a la aceleración comunicacional de la globalización- y las necesidades de sus jóvenes estudiantes. Desde luego, estas herramientas son del agrado de los estudiantes, que demuestran mucho interés en ellas. Algunos docentes refieren que, al entrar en ese conflicto, es mejor estar a la vanguardia y usarlas, pues prohibirlas se hace cada vez más difícil y problemático debido a que muchos de los estudiantes ya tienen teléfonos móviles a los que acceden con relativa facilidad y de los que no están dispuestos a abrir mano en las aulas.

El uso más frecuente de la poca tecnología a la que tienen acceso, sin embargo, es el de servicios de mensajería instantánea y aplicaciones de redes sociales y de streaming que utilizan para visualizar contenidos en línea y compartirlos con sus compañeros. Por esta razón, algunos de los docentes de informática expresaban una visión negativa de las TIC como elementos distractores, aduciendo en ocasiones un discurso conser-

19 Entrevista realizada el 3 de marzo de 2020 a una profesora en la ENOSIMAR.

${ }^{20}$ Entrevista realizada el 24 de marzo de 2020 a un profesor en su domicilio. 
Jaili Ivinai Buelvas Diaz, María Sirex Consuegra Díaz-Granados, David Felipe Henao Heuta, Juliana López Cuervo, John Jairo Osorio Giraldo, Laura Daniela Pardo Castellanos, Camila Peña Gómez

Teclados de cartón. Tecnologías, identidad y comunicación entre jóvenes estudiantes de la ENOSIMAR en Mitú (Vaupés), Amazonía colombiana

vador y moralizante que ve a las tecnologías como un factor perturbador de las tradiciones y una fuente de acceso a contenidos "prohibidos" (sexo, drogas, prácticas de magia) que han introducido diversas problemáticas.

Por ello, en vez de ver a las TIC como un aliado educativo y hacer un uso creativo y estratégico de ellas, muchas veces los profesores y las instituciones tienden a restringir, e incluso a prohibir, el uso de aparatos tecnológicos durante las clases, ignorando que podrían hacer una pedagogía de las comunicaciones que les permita aprovechar la disponibilidad de estos dispositivos como herramientas de acceso e intercambio de conocimientos, saberes y experiencias que pueden poner a los jóvenes estudiantes en contacto con las ciencias, el arte, la música, la literatura y los idiomas.

Frente a los resultados de esta implementación de las pedagogías usando herramientas de las TIC, la mayoría de los estudiantes mostraba disconformidad por la falta de equipos para la interacción; el aprendizaje es muy difícil cuando se trabaja en grupos de más de seis o siete estudiantes con un mismo computador. Adicionalmente, ha faltado un compromiso institucional con el aterrizaje a los entornos locales y las particularidades étnicas de los contenidos dados en estas capacitaciones. En ninguno de los intentos gubernamentales se ha considerado si estos son apropiados para el contexto cultural del Vaupés, el rango etario de los estudiantes y los conocimientos previos en relación con las TIC, así como tampoco se han cuestionado la generación de contextos de uso que la comunidad encuentre beneficiosos en su cotidianidad (López, 2008).

\section{Contenidos y usos de internet: transformaciones identitarias}

Una de las mayores preocupaciones tanto de funcionarios como de docentes radica en que encuentran a la tecnología como un elemento incompatible con las identidades indígenas. Este imaginario se enmarca en la comprensión occidental de la alteridad. Mitú, como ciudad amazónica, evoca muchos de los conflictos que conjugan modernidad con etnicidad (Alexiades y Peluso, 2016) y se localiza en los límites de un sistema social, como una territorialización de un "Otro" (Martins, 2009). Occidente construye la alteridad indígena a partir de considerar que son objetos inmutables en el tiempo, sin transformaciones ni historia, $y$, particularmente, como si se hubiesen quedado en un tiempo pretérito (Fabian, 1983). Este imaginario se expresa en el Vaupés con un temor a que la tecnología "penetre" en la cotidianidad de los pueblos indígenas y "altere" su identidad, encontrándonos con opiniones que aseveran que "Lo más difícil de la tecnología en el departamento es que se logre implementar [...]'sin tocar la parte cultural de ellos. Es el gran reto, que no se trate de imponer". ${ }^{21}$ Los entrevistados afirman

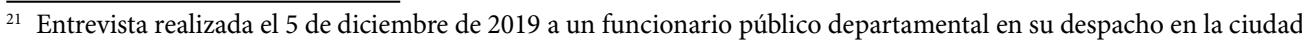
de Mitú. 
constantemente que los usos de internet no son los "ideales". Existe un consenso entre los docentes de que debe formarse a los jóvenes para que internet pueda utilizarse más allá del uso desmedido de las redes sociales, que son desprestigiadas dentro del amplio espectro de contenidos que existen en internet. El temor por la inestabilidad de la identidad permea las discusiones, así como también el riesgo inherente que conlleva el acceso a internet de que los jóvenes accedan irrestrictamente al océano de contenidos que allí se alojan sin ninguna supervisión.

La visión de algunos de los docentes entrevistados es catastrófica. Manifiestan que los estudiantes no le dan un uso a internet para los estudios, sino que lo usan para chatear, jugar o mirar páginas de pornografía. Estas visiones se amparan en sucesos ocurridos en el colegio y que han alimentado, con razón, la preocupación de los docentes. Por ejemplo, una docente nos comentó: "El año pasado tuvimos niñas que se hacían eso del cutting, ${ }^{22}$ y se mandaban fotos entre ellas de cómo se cortaban y todo eso". ${ }^{23}$ Las medidas restrictivas de colocar contraseñas o impedir el acceso a las salas de informática ha controlado en parte el acceso a internet, pero no ha disminuido la posibilidad de usar los celulares inteligentes y las zonas de wifi gratuito para los usos ya referidos. Algunos consideran no solo que los jóvenes del Vaupés no están preparados para acceder a la infinidad de contenidos de la web, sino que, además, afirman que los contenidos que allí encuentran son mal interpretados y tergiversados. Según los profesores y funcionarios, los preceptos de la modernización neoliberal que toman un cuerpo virtual en internet han generado impactos negativos: "El internet ha tenido mucho impacto negativo, sus formas de vestir, sus costumbres, su cultura, todo eso lo van perdiendo". 24 "El impacto de la tecnología ha sido negativo, porque los jóvenes se han transformado por lo que ven en las redes, tatuajes, pelos pintados y parados.".

Uno de los funcionarios entrevistados nos manifestó que, dentro de su experiencia visitando colegios, ve con preocupación que no hay un control sobre lo que se ve y se busca en internet, por lo que ha compartido esta inquietud con los docentes. Entiende a internet como "un mundo por descubrir, donde hay de todo, bueno y malo. [...] Ellos piensan que nunca nada malo va a pasar" ${ }^{26}$ Adicionalmente, reproduce el estereotipo del indígena inocente o el "buen salvaje" (Bartra, 2008), asumiendo que el desconocimiento se apodera inevitablemente del pensamiento de las comunidades indígenas con relación a los posibles riesgos que se pueden encontrar en internet. Esta visión le endilga la responsabilidad de los incidentes negativos, de los usos y de las acciones de los estudiantes a su pertenencia étnica, pero no cuestiona las fallas en todos los niveles

22 El cutting es el acto de cortarse las muñecas con objetos afilados hasta producirse heridas superficiales.

23 Entrevista realizada el 24 de marzo de 2020 a una profesora en su domicilio.

24 Entrevista realizada el 24 de marzo de 2020 a una profesora en su domicilio.

25 Entrevista realizada el 24 de marzo de 2020 a un profesor en su domicilio adjunto a la ENOSIMAR.

${ }^{26}$ Entrevista realizada el 5 de diciembre de 2019 a un funcionario público departamental en su despacho en Mitú. 
Jaili Ivinai Buelvas Diaz, María Sirex Consuegra Díaz-Granados, David Felipe Henao Heuta, Juliana López Cuervo, John Jairo Osorio Giraldo, Laura Daniela Pardo Castellanos, Camila Peña Gómez

Teclados de cartón. Tecnologías, identidad y comunicación entre jóvenes estudiantes de la ENOSIMAR en Mitú (Vaupés), Amazonía colombiana

de los programas en la formación, capacitación y construcción de una mirada crítica frente a la información como posible factor decisivo en la creación de contextos benéficos de uso. Es también importante resaltar que este pensamiento expresa un deseo superficial de que "no cambien" su cultura con el uso de las TIC, pero no se cuestiona el modelo mismo de educación que, como lo hemos visto, promueve o ha provocado ese mismo desarraigo.

\section{Identidades, jóvenes y comunicación}

En materia de identidades, esta fragmentación de las subjetividades en la modernidad ha sido elaborada desde distintas perspectivas. Una de las vertientes aduce que la globalización ha venido a fragmentar procesos identitarios consolidados y a minar política y socialmente a los grupos culturales. Esta visión monolítica de la identidad desconoce que una mirada histórica revela que la identidad no ha sido nunca una entidad estática. En este contexto de transformaciones y múltiples tránsitos, es fundamental comprender la identidad no como un objeto fijo y acabado, sino como un proceso. Así, para Saurabh Dube (2010), las identidades se definen dentro de las relaciones históricas de producción, apropiación, consumo, modernidad, nación y globalización y surgen mediadas por los ajustes de género, raza y edad, arte y sexualidad, que están cambiando constantemente.

En la modernidad, las sociedades experimentan lo que Stuart Hall (2006) llama "crisis de identidad" (Hall, 2006, p. 4), en la que las constantes transformaciones permiten crear y apropiarse de formas identitarias que no se fijan permanentemente, sino que se encuentran en constante proceso de recreación. Los sujetos no se componen como entidades coherentes, sino que incorporan las contradicciones advenidas de la negociación con el pasado y la inserción en la modernidad. Este proceso puede estar influenciado por eventos conflictivos, por los diálogos con la memoria y por la creatividad cultural de las comunidades en sus respuestas al contexto cambiante. Las identidades se construyen en relación con el espacio y con el tiempo particular, creando una forma de estar en el mundo y de aprehenderlo. En estos procesos identitarios, las fronteras entre grupos sociales se redefinen, se expanden y se dilatan en constantes juegos de transculturación, interculturalidad, apropiación y consumo.

Al tratarse de un proceso móvil y transgeneracional, las transformaciones y continuidades del proceso de la identidad se manifiestan de manera mucho más dramática en los jóvenes. Algunos autores refuerzan la hipótesis de que aquellos que están inmersos en nuevas herramientas y redes digitales se involucran en una exploración sin precedentes del lenguaje, los juegos, la interacción social, la resolución de problemas y la actividad autodirigida que conduce a diversas formas de aprendizaje. Estas distintas formas de aprendizaje se reflejan en expresiones de identidad y en cómo los jóvenes 
expresan independencia y creatividad, y en su capacidad para aprender, tomar partido y pensar sistemáticamente (Buckingham, 2008). Lo que se asume comúnmente en este tipo de literatura es que las nuevas tecnologías influyen de manera inequívoca en los procesos identitarios de los jóvenes.

Tales discursos típicamente encarnan una forma de determinismo tecnológico. En este sentido, los usos que se hacen de la tecnología son solo una parte de la mucho más amplia reestructuración contemporánea de la sociedad y de las relaciones sociales, mediadas por formas de producción y acumulación capitalista, por ejemplo, las de la inversión en infraestructura, seguridad y control poblacional (Robin y Webster, 1988). No obstante, no se deben desconocer las fracturas de ese mismo proceso y los potenciales de resistencia, transformación y controversia que convoca la agencia de los sujetos en la interacción social; tal es el caso de las nuevas subjetividades que la era de internet ha producido y sigue produciendo (Bennett y Entman, 2000; Starr, 2004).

Circunscrito a las nuevas generaciones, no podemos aceptar acríticamente la idea del "nativo digital" con una consciencia elevada y una toma de posición consciente sobre sus procesos de opinión e identitarios, fruto de las nuevas tecnologías de la información y de la comunicación (Metzger y Flanagin, 2007). Así, no puede suponerse que la tecnología tenga efectos para provocar cambios sociales y psicológicos, independientemente de la forma en la que se use y de los contextos y procesos sociales en los que participe. Esta perspectiva defiende que estas plataformas trascienden las anteriores cadenas comunicativas y que sus contenidos pueden llegar a un público indeterminado, que puede ser incluso global. Es así como considera que el conocimiento y la comunicación en el mundo se han democratizado a través del uso de internet. En términos más generales, podría decirse que, a partir de posturas críticas, se ha desafiado la idea de que la "sociedad de la información" representa un nuevo modo de organización social, en el que las formas establecidas de actividad económica, política y social están siendo fundamentalmente alteradas como consecuencia inevitable de la tecnología.

Sin embargo, como acertadamente acota Buckingham (2008), la visión totalmente opuesta, es decir, la noción de que la tecnología está de alguna manera totalmente preformada por las relaciones sociales existentes, no se encuentra exenta de conflictos. Un postulado como este ignora el hecho de que las tecnologías tienen potencialidades inherentes o "posibilidades", como usos particulares; es mucho más fácil emplearlas para algunos propósitos que para otros y, al menos con los medios con los que contamos actualmente, pocas de estas posibilidades son inevitables. Esto no necesariamente desconoce que hay formas de uso alternativas y sorpresivas, así como la emergencia constante de nuevas potencialidades de la tecnología. La historia reciente está llena de ejemplos de consecuencias imprevistas e incluso usos subversivos de la tecnología. Aun así, las formas que adopta la tecnología son en gran medida moldeadas por los ac- 
Jaili Ivinai Buelvas Diaz, María Sirex Consuegra Díaz-Granados, David Felipe Henao Heuta, Juliana López Cuervo, John Jairo Osorio Giraldo, Laura Daniela Pardo Castellanos, Camila Peña Gómez

Teclados de cartón. Tecnologías, identidad y comunicación entre jóvenes estudiantes de la ENOSIMAR en Mitú (Vaupés), Amazonía colombiana

tores y las instituciones sociales que desempeñan un papel principal en su producción y en la determinación de dónde, cuándo y cómo se utilizará y por quién. Por lo tanto, un enfoque crítico sobre ambas posturas propone ir más allá de la noción de "tecnología" como una simple "causa" de cambio social, la idea de que la tecnología es la "consecuencia" de formas sociales preestablecidas e inmutables, al mismo tiempo que desafía la idea de la tecnología como un "arreglo" fácil para problemas sociales complejos.

Los jóvenes, en el centro de esta dicotomía, interactúan de formas diversas con las posibilidades de la tecnología en la medida de sus contextos sociales, como así también desafían las lógicas de sus posicionamientos en la estructura social. Sin embargo, no podemos tomar a la ligera la idea de la "generación digital" como un despertar cognitivo de la nueva generación, ya que esta ignora la banalidad de muchos de los nuevos usos de los medios. "Estudios recientes sugieren que los usos cotidianos de Internet de la mayoría de los jóvenes no se caracterizan por formas espectaculares de innovación y creatividad, sino formas relativamente mundanas de comunicación y recuperación de información" (Buckingham, 2008, p. 14). Puede citarse que hay poca evidencia de que la mayoría de los jóvenes estén usando internet para desarrollar conexiones globales; en la mayoría de los casos, internet parece usarse principalmente como un medio para reforzar las redes locales entre pares. Así también, muchas investigaciones muestran que no necesariamente las nuevas generaciones tienen mayores capacidades para enfrentarse con las tecnologías (Herring, 2008). Los ejemplos que hemos expuesto sobre la visualización de pornografía y la práctica del cutting en los jóvenes de Mitú se insertan en estos usos banalizados que muchos jóvenes hacen de las TIC. Adicionalmente, a pesar de los potenciales de las nuevas tecnologías, la mayor parte de sus posibilidades requieren inversiones en el marco del sistema global, que implican acceso a distintos tipos de capitales, entre los cuales el acceso a computadores, dispositivos, software y un gran ancho de banda son solo una parte. Así, la mayor parte de los beneficios de las tecnologías son bastante inaccesibles para la mayoría, excepto para las clases medias-altas. Considerando esto, aun con acceso monetario a los recursos, no pueden despreciarse las particularidades de la geopolítica en las cuales los territorios periféricos se insertan de manera asimétrica en el acceso digital.

Como hemos mostrado a lo largo del texto, la mayoría de las preocupaciones de quienes consideran que la tecnología mina el desarrollo identitario de los jóvenes indígenas en realidad se anclan en un prejuicio que se basa en la compresión espacio-temporal que occidente tiene del Otro (Fabian, 1983) y en la desigualdad en las estructuras profundas de funcionamiento de nuestra sociedad, que no permiten la comprensión de miradas desde la etnicidad a tecnologías que se presentan con propósitos homogeneizantes por la globalización. 
A pesar de eso, vemos que las formas apropiación/recepción de los medios digitales en comunidades indígenas dan cabida a nuevas e inesperadas formas de afianzamiento de su identidad, casi nunca contempladas por las políticas gubernamentales, y en gran parte de las veces en conjunción con actos que podríamos considerar críticos con los propósitos de este tipo de determinaciones oficiales (Brusse, Gardner, McAullay y Dowden, 2014; Carlson, 2013; Iseke-Barnes, 2002; Landzelius, 2004; Lumby, 2010).

Para Carlson (2013), el contexto australiano muestra un aumento del uso de redes sociales entre pueblos indígenas como forma de interacción cultural y para expresar y legitimar sus identidades frente a la poca atención que la academia le ha dedicado a estas nuevas formas de construcción comunitaria. Como la autora investigó en su doctorado, Facebook se ha vuelto un recurso fundamental en la autoconstrucción y exhibición de la identidad indígena en Australia; el uso de las redes sociales entre indígenas australianos no es una peculiaridad, sino algo cotidiano, y, en ellas, la interacción de los indígenas en internet no implica una matización de sus identidades culturales.

A pesar de que muchas investigaciones sugieren que los ciberespacios promueven espacios desincorporados donde las personas cambian y adaptan sus identidades, la autora defiende que los indígenas incorporen sus elementos identitarios en la interacción virtual. A pesar de que el intercambio no es cara a cara, los que interactúan son personas reales sometidas a condiciones similares de regulación y estos espacios ayudan a formar ideas sobre quiénes son las personas offline. Esto no indica que la comunicación online y offline sean solapables y absolutamente prístinas; según Carlson (2013), las personas crean performances sobre quiénes son en la red, lo que lleva a algunos indígenas a "aboriginalizar" sus perfiles para ser vistos como tales por los otros. El potencial creativo de las redes sociales es incluso más desafiante que la interacción cara a cara.

Este vínculo entre dos espacios que no están totalmente separados, sino que se interrelacionan, coincide con la perspectiva de Castells (2013), según la cual la comunicación está atravesada por redes de poder que las sobrepasan. Al llevar su argumento al contexto de las TIC, habría que considerar que, contrario a la noción contemporánea, la comunicación y sus dispositivos no solo se refieren a internet y a los computadores, sino también a formas de construcción de redes simbólicas y espacios de socialización.

El Vaupés es un espacio muy prolijo para identificar las interacciones entre identidad, educación, juventud y comunicación, debido a sus múltiples particularidades que lo insertan en ese espacio que integra una interfaz urbano-rural (Alexiades y Peluso, 2016) y que desafía, al mismo tiempo que interpreta, las lógicas fragmentadas de la modernidad.

Por medio de las observaciones y de la información recabada en la realización de los talleres, logramos identificar la inmensa curiosidad e interés que despiertan las 
Jaili Ivinai Buelvas Diaz, María Sirex Consuegra Díaz-Granados, David Felipe Henao Heuta, Juliana López Cuervo, John Jairo Osorio Giraldo, Laura Daniela Pardo Castellanos, Camila Peña Gómez

Teclados de cartón. Tecnologías, identidad y comunicación entre jóvenes estudiantes de la ENOSIMAR en Mitú (Vaupés), Amazonía colombiana

TIC en los jóvenes internos de la ENOSIMAR. Consideramos que existe un enorme potencial de trabajo que posibilitaría el desarrollo de las comunicaciones a nivel local y regional, convirtiéndose en una plataforma para la producción de contenidos propios que entren en diálogo con el resto de la sociedad, propiciando un intercambio cultural, educativo y político. Asimismo, las TIC podrían ser uno de los polos de desarrollo social y económico con enfoque territorial desde una perspectiva étnica, autónoma, que propicie la circulación de la información y fortalezca los flujos de la comunicación urbano-rural en un contexto de conexión global que podría ser útil en la formación, capacitación y profesionalización de los jóvenes según sus intereses.

Los usos comunicativos de las redes sociales u otras aplicaciones que se usan con internet no son de menor importancia. Vemos que la posibilidad de comunicación con familiares o amigos fortalece la identidad de los niños y jóvenes estudiantes internos de la ENOSIMAR, ya que muchos provienen de lugares selva adentro. Esto, entendiendo las posibilidades y limitaciones de la comunicación desde Mitú a otros municipios y comunidades del departamento. Algunos de los entrevistados identifican también otros beneficios potenciales de las TIC para los estudiantes.

El internet tiene otros beneficios que la gente no conoce, se puede estudiar una carrera
tecnológica, una carrera profesional por intermedio del internet. También se puede hacer
por internet el comercio electrónico, la gente no lo ha explotado, pero tiene en sus manos
un celular y dos zonas wifi, un sinnúmero de cosas que tiene el internet hoy en día. ${ }^{27}$

Dentro de los usos con posibilidades de exploración son destacados los de la investigación y formación de tipo técnica y tecnológica de manera virtual y a distancia. La llegada de este tipo de tecnologías ha permitido a muchas personas recibir educación y profesionalizarse; cada vez más jóvenes utilizan las salas y la conectividad a internet para acceder a la educación a distancia y a formación formal e informal complementaria en línea. Las apuestas educativas virtuales han comenzado a llegar incluso en los frentes de la educación superior, en los que algunos estudiantes, a través de una alianza con la Universidad Minuto de Dios, comenzaron a formarse virtualmente. Incluso el Ministerio ha venido incentivando a los jóvenes para que escojan carreras tecnológicas y utilicen con ese fin los espacios disponibles.

También se considera que los emprendimientos digitales son una nueva opción de negocio para muchas personas que ya comienzan a hacer envíos nacionales e internacionales de artesanías u otros productos propios.

Por su parte, las comunidades indígenas, más que oponerse o desincentivar el uso de las tecnologías de la información y comunicación -o de las redes sociales-, se es-

${ }_{27}$ Entrevista realizada el 4 de diciembre de 2019 a un funcionario público municipal en su despacho en la ciudad de Mitú. 
tán apropiando de estas herramientas para usos propios. Parece que la preocupación sobre proscribir o permitir el acceso no es de mayor relevancia para los miembros de las comunidades y solo atormenta y atiza los prejuicios a la población no indígena. $\mathrm{Al}$ interior de las comunidades, si bien en algunas personas existe un poco de resistencia a la tecnología, esto no es debido al temor, sino a la primera fase de limitaciones en el acceso definida por Van Dijk (1999): la ausencia de experiencia digital cuyas causas atraviesan la falta de interés, la ansiedad informática o el poco atractivo que las tecnologías les producen, debido a la falta de promoción del diálogo de la experiencia tecnológica con la experiencia comunitaria. Los jóvenes, en cambio, las están apropiando $\mathrm{y}$ aunque a veces no son escuchados dentro de sus comunidades, sus intereses pueden aportar en reafirmar su identidad étnica y comunicar sus culturas al mundo globalizado (Carlson, 2013).

Las posibilidades de utilizar las tecnologías contemporáneas y plasmar con ellas las culturas y cosmologías propias haría que los jóvenes indígenas se insertaran en la globalización en una postura más dinámica. Esta convicción la revela uno de los profesores entrevistados, al opinar:

Sería importante que ellos empezaran incluso a mostrar o a subir allí todo lo que ellos tienen en su territorio, o sea, sus caños, sus sitios elegantes, los animales, la maloka, su cultura, dar a conocer eso sería importante... jsí!, sería importante que estas tecnologías se conectaran con el contexto de la cultura, que mostraran lo que verdaderamente son esas comunidades para que sea como un conocimiento universal también. Mostrar lo de aquí, lo de nosotros, lo de la región. ${ }^{28}$

Las dificultades de que los programas de política pública consideren a este proceso como algo beneficioso y empiecen a trabajar en este sentido radican, como resulta evidente en nuestra discusión, no en el desconocimiento del "potencial" de la tecnología, sino en la preservación de estructuras sociales que se reflejan en la práctica de la gestión política (Buckingham, 2008). Esto pone en contraposición dos miradas contrarias sobre la tecnología, representadas por las concepciones indígenas y las del sistema del mundo neoliberal de la globalización.

En aras de la aclaración, afirmo que dos conceptos muy diferentes de la tecnología son el problema. Una visión occidental profundamente arraigada (basada en la metafísica) de la tecnología como ciencia aplicada a objetivos industriales (de fabricación) y comerciales, frente a una visión de la tecnología de los indios americanos, o más bien indígena, (basada en la metafísica) de la tecnología como prácticas y herramientas para mejorar nuestra vida en y con naturaleza. La concepción y las prácticas occidentales de la tecnología están ligadas al materialismo esencialmente centrado en el ser humano: la doctrina de que el bienestar físico y las posesiones mundanas constituyen el mayor bien y el más alto valor en la vida. Las concepciones y prácticas indígenas de la tecnología están integradas en una forma de vivir la vida que incluye dimensiones espirituales, físicas, emocionales e in-

${ }^{28}$ Entrevista realizada el 24 de marzo de 2020 a un profesor en su domicilio en la ciudad de Mitú. 
Jaili Ivinai Buelvas Diaz, María Sirex Consuegra Díaz-Granados, David Felipe Henao Heuta, Juliana López Cuervo, John Jairo Osorio Giraldo, Laura Daniela Pardo Castellanos, Camila Peña Gómez

Teclados de cartón. Tecnologías, identidad y comunicación entre jóvenes estudiantes de la ENOSIMAR en Mitú (Vaupés), Amazonía colombiana

telectuales emergentes en el mundo o, más exactamente, lugares particulares en el mundo. Los esfuerzos para abordar las necesidades de los desafíos tecnológicos de los nativos de América no deberían ser solo tokenismo educativo o simple fingimiento para la financiación. Se debe considerar e incorporar un cambio fundamental en la pedagogía; no deberíamos repetir los viejos patrones de replicar la estructura de poder (López, 2008, p. 115). ${ }^{29}$

Buscar el uso autónomo de estas herramientas TIC por parte de la comunidad educativa de la ENOSIMAR podría incentivar la creación de contenidos digitales propios que reivindiquen, por ejemplo, su etnicidad, el territorio o sus prácticas culturales. Estas experiencias pueden generar posibilidades coinvestigativas que aporten a la utilización de pedagogías y metodologías en esta institución a través del uso de las TIC, que, sumadas a las experiencias de vida de los jóvenes indígenas que allí asisten, conjugan un nicho interesante para trabajar de manera más etnográfica.

Ellos [los jóvenes indígenas internos] son muy ricos en cultura, en cosas que la gente no conoce y créame que [si] ellos se hicieran un video allá en su comunidad, [si] lo publicaran, ellos serían los futuros youtubers de la selva. En lo personal, yo creería que sería algo maravilloso. ${ }^{30}$

En cuanto al tema del uso que se le podría dar a las tecnologías en el Vaupés, nos llamó poderosamente la atención el diálogo entre tradición y modernidad que podría darse en la difusión de saberes y conocimientos autóctonos a través del uso creativo de las TIC. Por ejemplo, en un ejercicio de entrevistas realizado durante uno de los talleres como acercamiento a la producción digital sonora, identificamos que para los jóvenes participantes era más fácil entrevistarse y conversar en sus lenguas nativas, que les permiten expresarse de una manera más fluida y versátil con sus pares. ${ }^{31}$ Esta podría ser una oportunidad para promover el uso y la vitalidad de las lenguas indígenas, como así también para difundir la diversidad lingüística del territorio al resto de la sociedad nacional. Es la misma opinión de una de las profesoras con las que nos entrevistamos, que proponía las TIC como una manera de preservar, promover y diseminar las literaturas orales de los pueblos indígenas a través de series web y podcasts, entre otros contenidos que, con la capacitación y los equipos necesarios, podrían producir los jóvenes de Mitú.

Este panorama nos permite explorar un conjunto de elementos que crean el escenario de usos, consumos y apropiación de las tecnologías por parte de los estudiantes de la ENOSIMAR y la manera en cómo el acercamiento a estas herramientas les per-

\footnotetext{
29 Traducción propia.

${ }^{30}$ Entrevista realizada el día 24 de marzo de 2020 a un profesor en su domicilio.

31 Este interés fue evidente en las ocasiones en las que proyectamos películas y documentales, o cuando les mostramos las experiencias de jóvenes indígenas rapeando y haciendo música en sus lenguas. Esto les permitió a los jóvenes darse cuenta de que las TIC son poderosas herramientas de comunicación y, por ende, de lucha política; y nos llevó a reflexionar sobre el hecho de la subrepresentación de muchas experiencias étnico-raciales que no aparecen en el panorama de las producciones y los contenidos que circulan comúnmente en la web.
} 
Austral Comunicación

Volumen 9, número 2 (Diciembre de 2020): 635-675. ISSN 2313-9129

mite, o dificulta, el proceso de construcción de sus identidades. Podríamos atrevernos a decir que un acceso adecuado les garantizaría a estos jóvenes el derecho a la educación, al libre desarrollo de la personalidad, al desarrollo de sus capacidades y habilidades, al impulso de su creatividad e, incluso, que podría convertirlos en líderes y agentes transformadores de sus comunidades.

\section{Conclusiones}

Esta investigación muestra desde el estudio de caso de una ciudad amazónica las dificultades y potenciales de las TIC en contextos educativos indígenas. Mostramos la necesidad de complejizar la lógica del acceso y la consideración de las particularidades locales.

Los jóvenes de Mitú se encuentran con este tipo de tecnologías de manera tardía, generalmente en el contexto de su ingreso a la educación secundaria en la capital del departamento. Así, el uso de las TIC está asociado con procesos migratorios que definen en gran medida la historia y la política de la Amazonía. Analizar desde esta postura la incursión de los programas de TIC implementados en el Vaupés nos permite entender su relación con los sujetos indígenas como procesos anclados en los contextos políticos y sociales de la modernidad neoliberal. Debido a esto, la mayoría de los programas de acceso a las TIC se concentran y focalizan en Mitú, mientras que en el resto de las comunidades del departamento escasamente cuentan con el acceso a estas tecnologías.

De la misma manera, este acceso se aborda de manera instrumental en las políticas gubernamentales, que desconocen las condiciones sociales del país para garantizar su efecto y su utilidad en las lógicas locales.

Es evidente que hay un enorme desafío por diseñar y desarrollar políticas sobre las TIC que no se centren únicamente en proveer aparatos y equipos tecnológicos, aunque eso, junto con la conectividad, es condición sine qua non para el desarrollo de cualquier proyecto serio en la materia. Sin embargo, más importante aún, esa dotación debe ir acompañada de procesos pedagógicos de capacitación, formación y alfabetización digital que permitan cerrar la brecha tecnológica no solo en la tenencia de dispositivos, sino en la posibilidad de usarlos de maneras creativas, que conviertan a los jóvenes no en receptores pasivos, sino también en creadores de contenidos, en ciudadanos tecnológicos que puedan establecer diálogos constructivos con otros, construir con sus comunidades, avanzar en sus procesos de formación, producir y realizar contenidos que les permitan desarrollar ampliamente su identidad y difundirla a la sociedad y, por qué no, al mundo globalizado e interconectado de la sociedad contemporánea desterritorializada.

Consideramos que es importante pensar en pedagogías que les permitan a los jóvenes indígenas hacer una apropiación crítica de los medios virtuales y comprender 
Jaili Ivinai Buelvas Diaz, María Sirex Consuegra Díaz-Granados, David Felipe Henao Heuta, Juliana López Cuervo, John Jairo Osorio Giraldo, Laura Daniela Pardo Castellanos, Camila Peña Gómez

Teclados de cartón. Tecnologías, identidad y comunicación entre jóvenes estudiantes de la ENOSIMAR en Mitú (Vaupés), Amazonía colombiana

esta interacción que influye directamente en el modelo educativo nacional, en sus proyectos de vida y en sus identidades y promover un uso creativo para el fortalecimiento de la cultura y del territorio. Esta es una urgencia de los procesos que vinculan a las juventudes étnicas en contextos educativos y se muestra de manera contundente no solo en Colombia, sino en muchos contextos alrededor del globo.

La investigación sobre el uso de internet y las TIC resulta fundamental para proponer alternativas para un uso de las herramientas digitales que sea social, política y culturalmente pertinente, teniendo en cuenta el territorio y la población que las utiliza.

\section{Referencias}

Alexiades, M. y Peluso, D. (2016). La urbanización indígena en la Amazonia. Un nuevo contexto de articulación social y territorial. Gazeta de Antropología; 32(1), artículo 01. Obtenido de http://hdl.handle.net/10481/42869.

Appadurai, A. (2001). La Modernidad Desbordada: Dimensiones culturales de la globalización (Trad. G. Remedi). Montevideo: Ediciones Trilce/Fondo De Cultura Economica .

Bartra, R. (2008). El mito del salvaje. México, D. F.: Fondo de Cultura Económica.

Benedict, A. (1983). Imagined Communities: Reflections on the Origin and Spread of Nationalism. Londres: Verso.

Bennett, W. L. y Entman, R. M. (2000). Mediated politics: Communication in the future of democracy. Cambridge: Cambridge University Press.

Bernard, H. R. (1995). Research Methods in Anthropology: Qualitative and Quantitative Approaches (2a ed.). Lanham: AltaMira Press.

Brusse, C., Gardner, K., McAullay, D. y Dowden, M. (2014). Social media and mobile apps for health promotion in Australian Indigenous populations: Scoping review. Journal of medical Internet research, 16(12), e280.https://doi.org/10.2196/jmir.3614.

Buckingham, D. (2008). Introducing Identity. En Youth, identity, and digital media (pp. 1-24). Cambridge: The MIT Press.

Cabrol, M. y Severin, E. (2010). TICs en educación: Una innovación disruptiva. Aportes, 2, 1-2 Obtenido de https://publications.iadb.org/publications/spanish/document/ TICS-en-Educaci\%C3\%B3n-Una-Innovaci\%C3\%B3n-Disruptiva.pdf.

Carlson, B. (2013). The 'new frontier': Emergent Indigenous identities and social media. En Harris, M., Nakata, M. y Carlson, B. The politics of identity: Emerging indigeneity (pp. 147-168). Sídney: University of Technology Sydney E-Press.

Castells, M. (2013). Comunicación y poder. México, D. F.: Siglo XXI.

Consejo Nacional de Política Económica y Social. (2020). Tecnologías Para Aprender: Política Nacional Para Impulsar La Innovación En Las Prácticas Educativas A Través De Las Tecnologías Digitales (Documento CONPES Núm. 3988). Departamento 
Austral Comunicación

Volumen 9, número 2 (Diciembre de 2020): 635-675. ISSN 2313-9129

Nacional de Planeación, Ministerio de Educación Nacional, Ministerio de las Tecnologías de la Información y las Comunicaciones.

Departamento Administrativo Nacional de Estadistica. (s.f.). Estratificación socioeconómica. Obtenido de https://www.dane. gov.co/index.php/servicios-al-ciudadano/servicios-informacion/ estratificacion-socioeconomica\#preguntas-frecuentes.

Dube, S. (2010). Critical Crossovers: Postcolonial Perspectives, Subaltern Studies, and Cultural Identities. En Wetherell, M. y Mohanty, C. T. The SAGE handbook of identities (pp. 125-143). Los Ángeles: Sage publications. http://dx.doi. org/10.4135/9781446200889.n8.

El Congreso de Colombia. (11 de julio de 1994). Por la cual se establece el régimen de los servicios públicos domiciliarios y se dictan otras disposiciones. [Ley 142/1994]. DO: 14.433 .

El Congreso de Colombia. (30 de julio de 2009). Por la cual se definen principios y conceptos sobre la Sociedad de la Información y la Organización de las Tecnologías de la Información y las Comunicaciones-TIC-, se crea la Agencia Nacional de Espectro y se dictan otras disposiciones. [Ley 1341/2009]. DO: 47.426.

El Presidente de la República de Colombia. (13 de abril de 1918). Sobre gobierno y protección de los indígenas no civilizados de la región del Vaupés [Decreto 614/1918]. DO: 16.367.

Ministerio de Educación de Colombia. (2014). En TIC confío. Obtenido de http://www. enticconfio.gov.co/.

Evoh, C. J. (2007). ICTs, secondary education, and the knowledge economy: Exploring the roles of the private sector in post-apartheid South Africa. Journal of Education for International Development, 3(1), 1-25. Obtenido de http://www.equip123.net/ JEID/articles/5/ICTSecondaryEdKnowlEconomy.pdf.

Fabian, J. (1983). Time and the Other: How Anthropology Makes Its Object. Nueva York: Columbia University Press.

García Canclini, N. (1989). Culturas híbridas: Estrategias para entrar y salir de la modernidad. México, D. F.: Grijalbo.

González,F. (2003). ¿Colapso parcial o presencia diferenciada del Estado en Colombia?: Una mirada desde la historia. Colombia internacional, 58, 124-158. https://doi. org/10.7440/colombiaint58.2003.05.

González, F., Bolívar, I. y Vásquez, T. (2003). Hacia una mirada más compleja de La Violencia colombiana. Bogotá: CINEP.

Guins, R. y Sandoval, C. (2008). Learning race and ethnicity: Youth and digital media. Cambidge: The MIT Press.

Hall, S. (2006). Introduction: Who Needs Identity? En P. Du Gay \& S. Hall, Questions of cultural identity (pp. 1-17). Los Ángeles: Sage Publications. 
Jaili Ivinai Buelvas Diaz, María Sirex Consuegra Díaz-Granados, David Felipe Henao Heuta, Juliana López Cuervo, John Jairo Osorio Giraldo, Laura Daniela Pardo Castellanos, Camila Peña Gómez

Teclados de cartón. Tecnologías, identidad y comunicación entre jóvenes estudiantes de la ENOSIMAR en Mitú (Vaupés), Amazonía colombiana

Herring, S. C. (2008). Questioning the Generational Divide: Technological Exoticism and Adult Constructions of Online Youth Identity. En Buckingham, D. Youth, identity, and digital media (pp. 71-92). Cambridge: The MIT Press.

Hugh-Jones, S. (1981). Historia del Vaupés (Trad. C. Domínguez y J. A. Lucio). Maguaré, 1, 29-51. Obtenido de https://revistas.unal.edu.co/index.php/maguare/article/ view/29-51/14279.

Ingold, T. (2016). Conociendo desde dentro: Reconfigurando las relaciones entre la antropología y la etnografía. Etnografías contemporáneas, 2(2), 218-230. Obtenido de http://revistasacademicas.unsam.edu.ar/index.php/etnocontemp/article/view/96.

Iseke-Barnes, J. M. (2002). Aboriginal and Indigenous people's resistance, the internet, and education. Race Ethnicity and Education, 5(2), 171-198. https://doi. org/10.1080/13613320220139617.

Jackson, L. A., Zhao, Y., Kolenic, A. III, Fitzgerald, H. E., Harold, R. y Von Eye, A. (2008). Race, gender, and information technology use: The new digital divide. CyberPsychologyy Behavior, 11(4),437-442.https://doi.org/10.1089/cpb.2007.0157.

Landzelius, K. (2004). Native on the net: Indigenous and diasporic peoples in the virtual age. Londres: Routledge.

López, A. (2008). Circling the Cross: Bridging Native America, Education, and Digital Media. En Guins, R. y Sandoval, C. Learning race and ethnicity: Youth and digital media (pp. 109-126). Cambridge: The MIT Press.

Lumby, B. (2010). Cyber-indigeneity: Urban indigenous identity on Facebook. The Australian Journal of Indigenous Education, 39(S1), 68-75.

Majoka, M. I., Fazal, S. y Khan, M. S. (2013). Implementation of Information and Communication Technologies (ICTs) in Education Course: A Case from Teacher Education Institutions in Pakistan. Bulletin of Education and research, 35(2), 37-53. Obtenido de https://files.eric.ed.gov/fulltext/EJ1210447.pdf.

Martínez Acuña, Y. e Instituto Amazónico de Investigaciones Científicas. (2014/2015) Vive Digital Conecta el Vaupés y Rompe la Brecha digital del Departamento. CaoCao de la Ciencia, Tecnología e Innovación, Segunda Edición, 11-12.

Martins, J. de S. (2009). Fronteira: A degradação do outro nos confins do humano. São Paulo: Contexto.

Metzger, M. J. y Flanagin, A. J. (eds.). (2007). Digital Media, Youth, and Credibility. Cambridge: The MIT Press.

Mikre, F. (2011). The roles of information communication technologies in education: Review article with emphasis to the computer and internet. Ethiopian Journal of Education and Sciences, 6(2), 109-126. Obtenido de https://www.ajol.info/index. $\mathrm{php} / \mathrm{ejesc/article/view/73521.}$

Ministerio de las Tecnologías de la Información y la Comunicación. (10 de septiembre 
Austral Gmunicación

Volumen 9, número 2 (Diciembre de 2020): 635-675. ISSN 2313-9129

de 2019). Fichas Departamentales y Oferta Institucional. ColombiaTIC. Obtenido de https://colombiatic.mintic.gov.co/679/w3-article-125135.html.

Ministerio de Tecnologías de la Información y las Comunicaciones. (2 de febrero de 2020). Computadores para Educar (CPE). Ministerio de Tecnologías de la Información y las Comunicaciones. Obtenido de https://www.mintic.gov.co/portal/ inicio/Ministerio/Instituciones-Relacionadas/Computadores-para-Educar-CPE/.

Peña Márquez, J. C. (2011). Mitú: Ciudad amazónica, territorialidad indígena. Leticia: Universidad Nacional de Colombia, Sede Amazonia.

Robins, K. y Webster, F. (1988). Cybernetic capitalism: Information, technology, everyday life. En Mosco, V. y Wasco, J. (eds.). The Political Economy of Information (pp. 45-75). Madison: The University of Wisconsin Press.

Sánchez Cardozo, S. (s.f.). Vaupés: Pasado y presente [sin publicar].

Serje, M. (2011). El revés de la nación: Territorios salvajes, fronteras y tierras de nadie. Bogotá: Ediciones Uniandes/Universidad de los Andes.

Sistema Nacional de Evaluación y Gestión de Resultados. (2016). Evaluación de impacto del plan Vive Digital (p. 31). Departamento Nacional de Planeación, Dirección de Seguimiento y Evaluación de Políticas Públicas. Obtenido de https://colaboracion. dnp.gov.co/CDT/Sinergia/Documentos/Plan_Vive_Digital.pdf.

Starr, P. (2004). The creation of the media: Political origins of modern communications. Nueva York: Basic Books New York.

Trejos Rosero, L. F. (2015). El lado colombiano de la frontera colombobrasilera: Una aproximación desde la categoría de área sin ley. Estudios fronterizos, 16(31), 39-64. Obtenido de http://www.scielo.org.mx/scielo. php?pid=S0187-69612015000100003\&script=sci_arttext.

Urrutia, E. K. M., Urrutia, X. A. M. y Chiluisa, J. M. O. (2017). Las TICS en la educación intercultural. Revista Publicando, 4(11(1)), 369-379. Obtenido de https:// revistapublicando.org/revista/index.php/crv/article/view/531.

Van Dijk, J. (1999). The network society. Social aspects of new media. Sage Publications. Van Dijk,J.yHacker,K.(2003).The digital divideas a complex and dynamic phenomenon. The information society, 19(4), 315-326. https://doi.org/10.1080/01972240309487.

Wanderley, L. J. (2018). Repensando a noção de fronteira no contexto de reestruturação espacial da Amazônia no século XXI. Terra Livre, 1(46), 13-48. Obtenido de https:// www.agb.org.br/publicacoes/index.php/terralivre/article/view/681/1287.

Warschauer, M. (2004). Technology and social inclusion: Rethinking the digital divide. Cambridge: MIT Press.

Wicks, P. G., Reason, P. y Bradbury, H. (2008). Living Inquiry: Personal, Political and Philosophical Groundings for Action Research Practice. En Reason, P. y Bradbury, H. The SAGE Handbook of Action Research: Participative Inquiry and Practice. (pp.15-30). Los Ángeles: Sage Publications. 